\title{
Differenzierung und Integration: Konfessionalisierung im frühneuzeitlichen Gesellschaftssystem. Das Beispiel der habsburgischen Vorlande
}

\section{Von Rudolf Schlögl}

Wirft man einen Blick in die 1797 von Alphonso Lugo, Doktor der Rechte und Professor der Politischen Wissenschaften und des Geschäftsstils, verfaßte „Statistik der Kaiserlich Königlichen Vorlande, “ so erfährt man unter anderem, daß, von einigen Orten abgesehen, in denen sich „Reformierte und evangelisch-lutherische Religionsverwandte “ vorfinden, die „vorländischen Unterthanen der römisch-katholischen Kirche zugethan" sind. Interessanter als die Konfessionszugehörigkeit an sich ist für Lugo allerdings der Gewerbefleiß der Nichtkatholiken: Die nach Konstanz aus Genf eingewanderten reformierten Familien brachten das Uhrmachergewerbe mit, und die wenigen in der Grafschaft Hohenberg lebenden Wiedertäufer sind wegen „ihres hohen Fleißes und ihrer landwirtschaftlichen Kenntnisse " als landwirtschaftliche Pächter geschätzt, „ob sie gleich nicht gesetzmeßig geduldet werden. ${ }^{\text {"1 } 1}$ Der Unterschied der Konfessionen prägte zwar weiterhin die Wahrnehmung der politischen und sozialen Landschaft am Ende des 18. Jahrhunderts, so kann man dem entnehmen, aber die konfessionelle Differenz war bereits in ihrer Eigenwertigkeit verblaßt. Sie hatte sich ökonomisch eingefärbt, so daß aus Konfessionsgruppen Gruppen unterschiedlichen Gewerbefleißes und gewerblicher Fähigkeiten wurden. Am Horizont ist bereits die These von der katholischen Inferiorität wahrzunehmen, die Max Weber schließlich zu seiner Hypothese über das protestantische Fundament des Kapitalismus inspirieren sollte. ${ }^{2}$

1. Alphonso Lugo, Statistik der Kaiserlich Königlichen Vorlande, in: Fritz Metz (Hg.), Vorderösterreich. Eine geschichtliche Landeskunde, 2. Aufl., Freiburg 1976, S.797-818, hier: S.797.

2. Max Weber, Die Protestantische Ethik und der Geist des Kapitalismus, in: ders., Gesammelte Aufsätze zur Religionssoziologie I, 9. Aufl., Tübingen 1988, S.1-236. Die Kritik an dieser These ist neuerdings zusammengefaßt bei Hans-Christoph Schröder, Max Weber und der Geist des Puritanismus, in: GG 21 (1995), S. 459-478. Die fundamentale methodische Kritik ist formuliert bei Niklas Luhmann, Gesellschaftsstruktur und Semantik. Studien zur Wissenssoziologie der modernen Gesellschaft, Bd.3, Frankfurt/M. 1993, S. 343 ff. - Die Feststellung des Statistikers Lugo ist bereits ein Teil dieses Diskurses, der seine Wurzeln offenbar in der Erfahrung des Siebenjährigen Krieges hatte und das katholische Selbstvertrauen nachhaltig erschütterte. Das Argu- 
Es ist ein Gemeinplatz der Frühneuzeitforschung, daß der größte Teil des 16. und wenigstens die erste Hälfte des 17. Jahrhunderts von anderen Wahrnehmungen gekennzeichnet war. Die Verfestigung der Glaubensspaltung zu kirchlich organisierten Konfessionen vollzog sich als ein Lebensbereiche umstürzender und wegen der christlichen Weltdeutungshoheit auch absoluter Prozeß, der im Bewußtsein der Zeitgenossen das Heil der Seele und die Möglichkeit einer zuträglichen irdischen Ordnung gleichermaßen betraf.

Die Geschichtswissenschaft hat dem Rechnung getragen, indem sie die Konfessionsbildung zu einem zentralen Thema in der Erforschung der frühen Neuzeit machte. Es ist gewiß nicht übertrieben, wenn man hier eine der wichtigsten Antriebskräfte für die Herausbildung der Neueren Geschichte im Sinn von early modern history als eigenständigem universitären Fach und gleichzeitig für die methodischen Innovationen in der Frühneuzeitforschung identifiziert.

Das Konfessionalisierungsparadigma entstand im Verlauf der siebziger Jahre aus dem Versuch, Modernisierungstheorie und Grundannahmen der Systemtheorie für das Verständnis gesellschaftlicher Entwicklungsprozesse in der frühen Neuzeit fruchtbar zu machen. Inhaltlich verbanden seine beiden wichtigsten Protagonisten, Wolfgang Reinhard und Heinz Schilling, die als hauptsächlich kulturell-religiösen Vorgang verstandene Konfessionsbildung, wie sie bereits Ernst Walter Zeeden gezeichnet hatte ${ }^{3}$, und das von Gerhard Oestreich ausgearbeitete Konzept der Sozialdisziplinierung ${ }^{4}$ zu einem Gesamtmodell, das die strukturellen Parallelen in der Herausbildung aller Konfessionen des westeuropäischen Christentums betonte und im Prozeß der konfessionellen Differenzierung die Kernlinie der Gesellschaftsgeschichte zwischen der Mitte des 16. und der Mitte des 17. Jahrhunderts identifizierte. Vor allem der Rückgriff auf Gerhard Oestreichs Konzept der Sozialdisziplinierung verschaffte dem Vorgang der Staatsbildung eine zentrale Stellung in diesem Erklärungsansatz. Die gesellschaftsgeschichtliche Dimension des Mo-

ment war dann, daß der protestantische Erfolg in weltlichen Angelegenheiten seinen Grund im Unglauben dieser Christen habe. Statt in die Kirche zu gehen, widmeten sie sich ihren Geschäften. Die katholische Seite diskutiert also nicht primär entlang der Unterscheidung Erfolg/Nichterfolg, sondern orientiert sich an religiös/irreligiös.

3. Ernst Walter Zeeden, Die Entstehung der Konfessionen. Grundlagen und Formen der Konfessionsbildung im Zeitalter der Glaubenskämpfe, München, Wien 1965.

4. Gerhard Oestreich, Geist und Gestalt des frühmodernen Staats, Berlin 1969; ders., Strukturprobleme der Fruihen Neuzeit, Berlin 1980. Eine Rekonstruktion des Konzepts der Sozialdisziplinierung bei Winfried Schulze, Gerhard Oestreichs Begriff „Sozialdisziplinierung in der Frühen Neuzeit", in: ZhF 14 (1987), S. 265-302. 
dells wird von der Annahme unterstrichen, im Konfessionalisierungsprozeß eine entscheidende Stufe in der Herausbildung der Europäischen Moderne zu identifizieren. Heinz Schilling erkennt daher in der Konfessionalisierung einen Vorgang von universalhistorischer Dimension, der die zweite Hälfte des 16. Jahrhunderts zu einer "Vorsattelzeit" der Moderne werden läßt. ${ }^{5}$ Wolfgang Reinhard vertrat dagegen von Anfang an eine andere Argumentationslinie: Er versteht Konfessionalisierung zunächst als Prozeß der Kirchenbildung, dessen weitere Auswirkungen auf Gesellschaft und Staat als nichtintendierte Nebenfolgen eines im Kern religionsgeschichtlichen Vorganges anzusehen sind. ${ }^{6}$ Absichten und Ziele rücken damit in den Vordergrund. Konfessio-

5. Heinz Schilling, Die Konfessionalisierung im Reich. Religiöser und gesellschaftlicher Wandel in Deutschland zwischen 1555 und 1620, in: HZ 246 (1988), S. 1-45. Der Stand der Diskussion aus seiner Sicht ist zusammengefaßt bei Heinz Schilling, Die Konfessionalisierung von Kirche, Staat und Gesellschaft - Profil, Leistung, Defizite und Perspektiven eines geschichtswissenschaftlichen Paradigmas, in: Wolfgang Reinhard, Heinz Schilling (Hgg.), Die katholische Konfessionalisierung. Wissenschaftliches Symposion der Gesellschaft zur Herausgabe des Corpus Catholicorum und des Vereins für Reformationsgeschichte 1993, Münster 1995, S.1-49, das Zitat S.33. In diesem Beitrag findet sich auch die wichtigste Literatur zitiert. Zur konzeptionellen Formung einer Europäischen Geschichte jetzt fruchtbar gemacht bei Heinz Schilling, Die neue Zeit. Vom Christenheitseuropa zum Europa der Staaten. 1250-1750, Berlin 1998: Schilling verschiebt den Umbruch zur Moderne von der „üblichen“ Epochenschwelle um 1500 auf das Ende des 16. und die erste Hälfte des 17. Jahrhunderts. Siehe dazu auch ders., Reformation - Umbruch oder Gipfelpunkt einer Temps des Réformes?, in: Bernd Moeller (Hg.), Die frühe Reformation in Deutschland als Umbruch. Wissenschaftliches Symposion des Vereins für Reformationsgeschichte 1996, Gütersloh 1998, S.13-34. Eine Zusammenfassung des Forschungsstandes und der Diskussion findet sich bei Heinrich Richard Schmidt, Konfessionalisierung im 16. Jahrhundert, München 1992. - Eine eigene Position zum Konfessionalisierungsbegriff bezieht Horst Rabe, Deutsche Geschichte 1500-1600. Das Jahrhundert der Glaubensspaltung, München 1991. Rabe bleibt beim Begriff „Gegenreformation, “ bezeichnet sie aber als „katholische Konfessionalisierung" und will "Konfessionalismus" als Epochenschwelle gelten lassen (ebd., S. 514f.). Damit rückt Rabe wieder sehr nahe an Zeeden und entsprechend strukturiert das Konfessionalisierungsparadigma seine Gesamtdarstellung nicht im Kern. Dies scheint auch an der starken Konzentration auf die Geschichte des handelnden Entscheidens zu liegen. Rabe spricht allein von „Konfessionalisierung der Po-

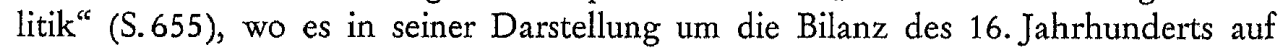
struktureller Ebene geht.

6. Wolfgang Reinhard, Zwang zur Konfessionalisierung? Prolegomena zu einer Theorie des konfessionellen Zeitalters, in: ZhF 10 (1983), S. 257-277; noch einmal formuliert und verfeinert unter Aufnahme der Forschungsdiskussion in ders., Was ist Katholische Konfessionalisierung?, in: Wolfgang Reinhard, Heinz Schilling (Hgg.), Katholische Konfessionalisierung (wie Anm.5), S.419-452; zuletzt ders., Sozialdiszipli- 
nalisierung vollzog sich demnach als planvolles Geschehen, das seine wesentliche Triebkraft aus dem Zwang erhielt, sich in der Konkurrenz der Glaubensoptionen jeweils zu behaupten.

Diese Unterschiede in der Argumentation haben den wissenschaftlichen Erfolg des Konfessionalisierungsparadigmas und sein Anregungspotential auf einer Vielzahl von Themenfeldern nicht beeinträchtigt. Neuerdings allerdings mehren sich Kritik und Gegenentwürfe.

Eine im Grundzug selbst konfessionalistische Argumentation nimmt Anstoß am übergreifenden Anspruch des Modells und betont die Sonderrolle der katholischen Gegenreformation, die sich vom Konfessionalisierungsparadigma nicht erfassen lasse, weil die katholische Kirche sich auch in der Gegenreformation in Kirchlichkeit und Dogma nicht wesentlich verändert habe. Deswegen könne allenfalls von „katholischer Reform“ die Rede sein. Da zusätzlich an die Stelle generalisierender historischer Modellbildung das Verfahren historistisch-individualisierender Typologisierung gesetzt werden soll $^{8}$, wird hier eher eine konfessionell-historiographische Abwehrposition als ein argumentativ und systematisch weiterführender Beitrag erkennbar.

Auch wo der heuristische Wert des Konfessionalisierungsparadigmas nicht grundsätzlich in Zweifel gezogen wird, ruft der auf den Staat konzentrierte Grundzug des Modells neuerdings Widerspruch hervor. Die Kritik entzündet sich dann an einem etatistischen Verständnis von Sozialdisziplinierung und betont dagegen den gesellschaftlichen Regelungsbedarf, der soziale Kontrolle in allen Sozialzusammenhängen unabhängig von staatlicher Initiative entste-

nierung - Konfessionalisierung - Modernisierung. Ein historiographischer Diskurs, in: Nada Boškovska Leimgruber (Hg.), Die Frühe Neuzeit in der Geschichtswissenschaft. Forschungstendenzen und Forschungserträge, Paderborn usw. 1997, S. 39-55.

7. Noch sehr prononciert in Wolfgang Reinhard, Zwang (wie Anm.6), S.257, $268 \mathrm{ff}$; in den jüngeren Veröffentlichungen steht der Staat als Protagonist nicht mehr so sehr im Vordergrund, so daß es Reinhard eher auf strukturelle Parallelen zwischen staatlicher Disziplinierung und kirchlicher Frömmigkeitsformung ankommt: Reinhard, Katholische Konfessionalisierung (wie Anm. 6), S.432 ff.; vgl. auch ders., Reformation, Counter-Reformation, and the Early Modern State. A Reassessment, in: The Catholic Historical Review 75 (1989), S. 383-404.

8. Walter Ziegler, Altgläubige Territorien im Konfessionalisierungsprozeß, in: Anton Schindling, Walter Ziegler (Hgg.), Die Territorien des Reichs im Zeitalter der Reformation und Konfessionalisierung. Land und Konfession 1500-1650, Bd.7, Münster 1997, S. 67-90, bes. S. 88 f.; ebenso bereits ders., Typen der Konfessionalisierung in katholischen Territorien Deutschlands, in: Reinhard, Schilling (Hgg.), Katholische Konfessionalisierung (wie Anm. 5), S. 405-418. 
hen ließ ${ }^{9}$, oder sie setzt gegen den Staat als treibende Kraft der Konfessionalisierung das Proprium der Kirche und die Dynamik der religiösen Kräfte. ${ }^{10}$ Ein anderer, an Max Weber orientierter Vorschlag sieht nicht im Verhältnis von Kirche und Staat das zentrale Problem, sondern identifiziert in der bürokratischen Modernisierung beider Bereiche den entscheidenden Entwicklungsschub des Konfessionalisierungsprozesses, wobei das sinnstiftende Potential religiöser Weltdeutung als ein gegenüber politischen und anderen Interessen eigenständiger Wirkfaktor ausgezeichnet wird. ${ }^{11}$ Dagegen kommt eine jüngst vorgetragene, explizit systemtheoretische Deutung des Konfessionalisierungsparadigmas in der Untersuchung territorialfürstlicher Konfessionswahl umgekehrt zu dem Schluß, daß die Eigengesetzlichkeiten politischen Handelns für sich standen und der theologische Wahrheitsdiskurs nur die Argumentationsmöglichkeiten auf diesem Feld vorstrukturierte. ${ }^{12}$ Umgekehrt

9. Heinrich Richard Schmidt, Sozialdisziplinierung? Ein Plädoyer für das Ende des Etatismus in der Konfessionalisierungsforschung, in: HZ 265 (1997), S.639-682; zur etatistischen Sichtweise Gerhard Oestreichs vgl. auch Günther Lottes, Disziplin und Emanzipation. Das Sozialdisziplinierungskonzept und die Interpretation der frühneuzeitlichen Geschichte, in: Westfälische Forschungen 42 (1992), S.63-74. Die Gegenposition Heinz Schillings ist zu finden in: ders., Disziplinierung oder „Selbstregulierung der Untertanen“. Ein Plädoyer für die Doppelperspektive von Makro- und Mikrohistorie bei der Erforschung der frühmodernen Kirchenzucht, in: HZ 264 (1997), S. 675-691.

10. Anton Schindling, Konfessionalisierung und Grenzen von Konfessionalisierbarkeit, in: Schindling, Ziegler (Hgg.), Die Territorien des Reichs (wie Anm. 8), S.9-44, hier: S. 11, 42. Neben die Konfessionalisierung setzt Schindling dann Säkularisierung als eine zweite, wirkmächtige Potenz, ohne allerdings das Verhältnis beider Prinzipien zueinander näher zu erläutern. Vgl. dazu jetzt auch Heinz Schilling, Der religionssoziologische Typus Europa als Bezugspunkt inner- und interzivilisatorischer Gesellschaftsvergleiche, in: Hartmut Kaelble, Jürgen Schriewer (Hgg.), Gesellschaften im Vergleich. Forschungen aus Sozial- und Geschichtswissenschaften, Berlin usw. 1998, S. 41-52, bes. S. 42 ff. Auf die Verbindung von Konfessionalisierung und Säkularisierung hebt auch ab Harm Klueting, Das konfessionelle Zeitalter 1525-1648, Stuttgart 1989, S. 362 ff. Allerdings wird in der Darstellung mehr die zeitliche Aufeinanderfolge als die strukturelle Parallelität hervorgehoben. Mit einer deutlichen Akzentuierung des Staatsbildungsprozesses und der Säkularisierung gegenüber der Konfessionalisierung: Michael Stolleis, „Konfessionalisierung" oder „Säkularisierung" bei der Entstehung des frühmodernen Staates, in: Ius Commune 20 (1993), S. 1-24.

11. Werner Freitag, Konfessionelle Kulturen und innere Staatsbildung. Zur Konfessionalisierung in westfälischen Territorien, in: Westfälische Forschungen 42 (1992), S. 75-191, bes. S. 78-81.

12. Norbert Haag, Zum Verhältnis von Religion und Politik im konfessionellen Zeitalter - System- und diskurstheoretische Überlegungen am Beispiel der Lutherischen Erneuerung in Württemberg und Hessen, in: Archiv für Reformationsgeschichte 
legt die Entwicklung der lutherischen Staatslehre seit der zweiten Hälfte des 16. Jahrhunderts den Schluß nahe, die Theologie habe durch die Fortschreitung der Drei-Stände-Ordnung zunächst ihre Gleichberechtigung gegenüber einer auf Souveränität pochenden politischen Obrigkeit zu behaupten gesucht, im 17. Jahrhundert aber dann das Problem durch Abspaltung eines der weltlichen Obrigkeit verschlossenen „kirchlichen Innenraumes “ gelöst, von dem aus umgekehrt das Wirken der Politik am Maßstab des Evangeliums gemessen werden konnte. ${ }^{13}$

Man verliert leicht die Orientierung in dieser zerklüfteten Diskurslandschaft, aber sie läßt doch erkennen, wo das zentrale Problem des Konfessionalisierungsparadigmas zu suchen ist. Es liegt augenscheinlich in der Abgrenzung staatlicher und kirchlicher Entwicklungsprozesse und in der Frage, in welchem Wirkungsverhältnis sie zueinander stehen. ${ }^{14}$ Weder der von Heinz Schilling gebrauchte Begriff der Differenzierung noch die von Wolfgang Reinhard apostrophierten „unbeabsichtigten Folgewirkungen“ bieten hier offenbar eine für den mit der Vielfalt der Phänomene befaßten Historiker befriedigende Lösung.

Es sollte in dieser Situation naheliegen, die Frage neu zu stellen. Will man dabei auf die Ergebnisse der geleisteten Forschungs- und Systematisierungsarbeit nicht verzichten, so geht es dabei hauptsächlich um einen geschärften analytischen Apparat, der die Phänomene deutlicher voneinander abhebt und sie einander klarer zuordnet. Man kann das Problem versuchsweise auf eine andere Ebene verlagern und überlegen, ob sich nicht eine Lösung ergibt, wenn man Konfessionalisierung als Symptom eines tieferliegenden Umstrukturierungsprozesses begreift, der das Verhältnis von Politik und Religion, von

88 (1997), S. 166-198, bes. S. 176 ff.; im besonderen grenzt Haag sich ab gegen Manfred Rudersdorf, Lutherische Erneuerung oder Zweite Reformation? Die Beispiele Württemberg und Hessen, in: Heinz Schilling ( $\mathrm{Hg}$.), Die reformierte Konfessionalisierung in Deutschland - Das Problem der „Zweiten Reformation“. Wissenschaftliches Symposion des Vereins für Reformationsgeschichte 1985, Gütersloh 1986, S. 130-153.

13. Luise Schorn-Schütte, Obrigkeitskritik im Luthertum? Anlässe und Rechtfertigungsmuster im ausgehenden 16. und 17. Jahrhundert, in: Michael Erbe, Hans Fïglister u. a. (Hgg.), Querdenken. Dissens und Toleranz im Wandel der Geschichte. Festschrift zum 65. Geburtstag von Hans R. Guggisberg, Mannheim 1995, S. 253-270, bes. S. $265 \mathrm{ff}$.

14. Der europäische Horizont eröffnet hier sofort neue Frageperspektiven: Vgl. Olaf Mörke, ,Konfessionalisierung als politisch-soziales Strukturprinzip? Das Verhältnis von Religion und Staatsbildung in der Republik der Vereinigten Niederlande im 16. und 17. Jahrhundert, in: Tijdschrift voor sociale Geschiedenis 16 (1990), S.3160 , bes. S. 33-43. 
Staatlichkeit und Kirchenorganisation zur hierarchisch-feudalen Grundordnung der Gesellschaft betraf. Staats-„bildung“ und Kirchen- „, bildung“ - beide Begriffe verweisen auf das Entstehen institutioneller Zusammenhänge, die offenbar gegen bestehende Strukturmuster durchgesetzt werden mußten, und für den Fall der Staatsbildung zeigt etwa die Geschichte der Stände in hinlänglicher Deutlichkeit, daß moderne Staatlichkeit gegen die Adelsherrschaft entstand und letztlich sich durchsetzte, indem sie die feudale Hierarchie der Adelsgesellschaft zerstörte. Erst dieser Umbau der Differenzierungsmuster der europäischen Gesellschaften ermöglichte Politik als zentralisierten, machtbasierten Prozeß allgemeinverbindlicher Entscheidungsfindung und damit frühmoderne Staatlichkeit. Die Integration von Politik und Staat beruhte nicht einfach auf einer Steigerung von Differenzierung, sie trug in sich eine neue Form der sozialen Differenzierung. ${ }^{15}$

Analog kann dann Konfessionalisierung - oder auch katholische Reform als Vorgang gedeutet werden, indem es darum ging, Kirchlichkeit in ihrer institutionellen Form und sozialen Logik von den Strukturprinzipien der Adelsgesellschaft unabhängig zu machen und sie als sozialen Handlungsbereich mit eigener Handlungsrationalität zu etablieren.

Von diesem Punkt aus stellt sich die Hauptfrage der Konfessionalisierung neu. Nicht mehr das Verhältnis von religiösen und staatlichen Kräften ist das zentrale Problem, sondern: warum die ja auch bereits im Spätmittelalter vorhandenen theologischen Differenzen in der Römischen Kirche sich im Verlauf des 16. Jahrhunderts bis zur Trennung kirchlich verfestigter Konfessionen stabilisierten? Soweit erkennbar, hat die Konfessionalisierungsforschung diese Frage bislang nicht gestellt. Sie folgt dem Grundtenor der Reformationsgeschichte und diskutiert die Glaubensspaltung als einen weltgeschichtlich notwendigen Vorgang. Dabei wird übersehen, daß Gesellschaften sich eine Komplexitätssteigerung, wie die Konfessionalisierung sie mit sich bringt, nur unter bestimmten Umständen leisten können. Sie sind daher nicht zwangsläufig, sondern sie sind voraussetzungsvoll und deswegen zunächst unwahrscheinlich. ${ }^{16}$

15. Der system- und evolutionstheoretische Hintergrund dieser Argumentation ist entwickelt bei Niklas Luhmann, Die Gesellschaft der Gesellschaft, Bd. 2, Frankfurt am Main 1997, S. 595-618, 678-707. Rabe akzentuiert die Bedeutung des Umstandes, daß die katholische Kirche Adelskirche blieb, in einem anderen konzeptionellen Rahmen und mit einer anderen Erklärungsabsicht. Er nimmt dies als Erklärung für den langwierigen Verlauf der katholischen Reformprozesse: Rabe, Deutsche Geschichte (wie Anm. 5), S.654.

16. Dieser Perspektivenwechsel ist der entscheidende Gewinn, wenn man das Para- 
Die Hypothese wiirde dann lauten, daß aus der Abgrenzung der Konfessionen Kräfte erwuchsen, die auch in Richtung der Verselbständigung von Kirchlichkeit und Staatlichkeit gegenüber der Strukturlogik der Adelsgesellschaft wirkten. Konfessionalisierung wäre dann der Prozeß, in dem sich - vor dem Hintergrund eines gemeinsamen Problems - die strukturellen Entwicklungen in beiden Bereichen wechselseitig soweit verstärkten, daß es zu einer Verfestigung und schließlich Verkirchlichung der Glaubenstrennung kam.

Da die protestantische Kirchlichkeit wenigstens vordergründig sehr viel radikaler mit den Traditionen der Adelskirche brach, dürfte es aufschlußreich sein, einen katholischen Fall wie Vorderösterreich zu untersuchen. Der Umstand, daß der Staatsbildungsprozeß hier mit besonderen Hypotheken belastet war, macht ihn zusätzlich interessant, da man kaum der Gefahr unterliegt, das Eigengewicht auf dieser Seite des Prozesses zu überschätzen, aber andererseits auch die Problemstellen klarer hervortreten. In der Konsequenz aus den methodischen Überlegungen soll die katholische Reform zunächst aus herrschaftlicher Perspektive (I.), dann aus der kirchlichen Innensicht (II.) dargestellt werden. Ein knapper vergleichender Blick wird unsere Beobachtungen dann in den Rahmen der bisherigen Forschungsergebnisse zur katholischen Konfessionalisierung stellen (III.), um die Besonderheiten herauszuarbeiten und einige allgemeinere Schlußfolgerungen (IV.) zu ziehen.

\section{HERRSCHAFT UND KONFESSION}

Gemessen am Zustand der Landeshoheit in anderen Territorien wies die habsburgische Herrschaft in Vorderösterreich in der ersten Hälfte des 16. Jahrhunderts gleich eine ganze Reihe von Defiziten auf.

digma der Modernisierungstheorie durch evolutionstheoretische Grundannahmen ersetzt. Zur Modernisierungstheorie und ihren Aporien vgl. Thomas Mergel, Geht es weiterhin voran? Die Modernisierungstheorie auf dem Weg zu einer Theorie der Moderne, in: Thomas Mergel, Thomas Welskopp (Hgg.), Geschichte zwischen Kultur und Gesellschaft. Beiträge zur Theoriedebatte, München 1997, S. 203-232, bes. S.216220. Zur Evolutionstheorie in der Geschichtswissenschaft vgl. Niklas Luhmann, Geschichte als Prozeß und die Theorie sozio-kultureller Evolution, in: Karl-Georg Faber, Christian Meier (Hgg.), Theorie der Geschichte. Beiträge zur Historik, Bd.2: Historische Prozesse, S. 374-412; Luhmann, Die Gesellschaft der Gesellschaft (wie Anm. 15), Bd. 1, S. 413-430, 569-576. Der Perspektivenwechsel befreit aus der impliziten Teleologie der Modernisierungstheorien. Der Gewinn, der sich daraus etwa für die Reformationsgeschichte ergibt, ist gut sichtbar in Thomas Fuchs, Konfession und Gespräch. Typologie und Funktion der Religionsgespräche in der Reformationszeit, Köln usw. 1995. 
Es war den Habsburgern trotz erheblicher Anstrengungen im Spätmittelalter nicht gelungen, den Raum zwischen Tirol, Elsaß und Schwaben zu einem geschlossenen Herrschaftsgebiet auszubauen. Nach der gewaltsamen Emanzipation der eidgenössischen Orte und Herrschaften aus dem Verfassungsgefüge des Reiches waren in diesem Raum drei lockere, in separaten Lehenshöfen zusammengefaßte Besitzkomplexe übrig geblieben: Schwäbisch-Österreich im Osten, die alten Besitzungen im Breisgau, am Oberrhein, auf dem Schwarzwald und im Elsaß sowie schließlich der geschlossene Komplex Vorarlbergs. Die jeweils unterschiedliche Genese und der ganz unterschiedliche Charakter wurde auch in der Entwicklung der Landstände deutlich: im Sundgau und im Breisgau waren Adel, Prälaten und die Städte zusammen mit bäuerlichen Gemeinden vertreten ${ }^{17}$, während auf den schwäbischen wie den Vorarlberger Ständeversammlungen nur Städte und bäuerliche Gemeinden agierten, weil Klöster und Adel sich erfolgreich allen Versuchen widersetzt hatten, sie in die Landstandschaft zu ziehen. ${ }^{18}$ Überwölbt wurde diese Besitzagglomeration durch Reichsrechte, von denen sich allerdings nur die Reichslandvogtei einigermaßen im landes- oder territorialherrschaftlichen Sinn nutzbar machen ließ, während die Reichsunmittelbarkeit der Klöster und Städte für den Ausbau der Landesherrschaft einen Sperriegel darstellte, den man nur um den Preis des Bedeutungsverlustes durchbrechen konnte, wie das Beispiel von Konstanz nach 1547 vorführte.

Beherrscht wurden die vorderösterreichischen Lande während der ganzen uns hier interessierenden Zeit von Innsbruck aus, so daß auch die Gravitationskraft einer Residenz und des Hofes fehlte, wenngleich die 1510 eingerichtete Regierung in Ensisheim regional begrenzte Ersatzfunktionen übernahm. Sie war wie das Innsbrucker Regiment in Regierung und Kammer gegliedert, $1573 \mathrm{kam}$ in Innsbruck ein Hofrat hinzu, der die Inhaber der Hofämter und andere Ratgeber zusammenfaßte. ${ }^{19}$ Auf den unteren Ebenen war die habsbur-

17. Dieter Kurt Gustav Speck-Nagel, Die vorderösterreichischen Landstände im 15. und 16. Jahrhundert, Teil 1. Zur Geschichte, Institution und Wirkungsweise der Landstände im Elsaß, Sundgau, Breisgau und Schwarzwald, Diss. phil. Tübingen 1991, S. 22-27; Peter Blickle, Landschaften im Alten Reich. Die staatliche Funktion des gemeinen Mannes in Oberdeutschland, München 1973, S.130f.

18. Franz Quarthal, Landstände und landständisches Steuerwesen in SchwäbischÖsterreich, Stuttgart 1980, S. 80-97; Benedikt Bilgeri, Geschichte Vorarlbergs, Bd. III: Ständemacht, gemeiner Mann - Emser und Habsburger, Wien usw. 1997, S. 323 ff.; Blickle, Landschaften (wie Anm. 17) S. 74; 98; 105. In der Landvogtei Schwaben gab es nur bäuerliche Gemeinden in der Landstandschaft.

19. Josef Hirn, Erzherzog Ferdinand von Tirol. Geschichte seiner Regierung und seiner Länder, 2 Bde., Innsbruck 1885-1888, hier: Bd. 1, S. 469 f. Vgl. auch Dieter Stie- 
gische Herrschaft präsent durch ihre Landvögte, die Vögte und Richter der einzelnen Herrschaften sowie zusätzlich noch durch Landschreiber. Man gewinnt nicht den Eindruck eines sehr fein gegliederten und dichten Verwaltungsapparates, allerdings mag dieser Mangel durch die geringe Größe der einzelnen Herrschaften und die Überlagerung von Zuständigkeiten, die sich aus den übereinander geschobenen Rechtsschichten ergab, ausgeglichen worden $\operatorname{sein}^{20}$

Ein weiteres Problem verstärkte die mangelnde Zentrierung. Das Haus Habsburg verzichtete bis ins 17. Jahrhundert darauf, der dynastischen Dynamik durch eine Haus- und Primogeniturordnung zu steuern. ${ }^{21}$ Für die Vorlande ergab sich daraus, daß von der Mitte des 16. bis zur Mitte des 17. Jahrhunderts Kaisertum und vorländische Regentschaft nur in wenigen Jahren zusammenfielen, weswegen auch die institutionelle Konkurrenz von Reichsrechten und landesherrlichen Ansprüchen, wie sie insbesondere in den Appellationsprivilegien des Adels und der Klöster zum Ausdruck kam ${ }^{22}$, nicht moderiert werden konnte. Außerdem setzte sich die weitere Aufsplitterung in kleinere Herrschaftseinheiten und Nebenlinien ungebremst fort, wie es mit der Herrschaft Karls, des Sohnes von Ferdinand I., in der Markgrafschaft Burgau von 1595 bis 1618 sowie schließlich durch die Begründung der Tiroler Linie durch Leopold geschah.

Trotz dieser herrschaftstechnisch schwierigen Ausgangssituation - oder besser, gerade wegen ihr - ergaben sich eine Vielzahl von Feldern, auf denen der Religionsbann exekutiert und das landesherrliche Kirchenregiment, denn

vermann, Österreichische Vorlande, in: Schindling, Ziegler (Hgg.), Die Territorien des Reichs (wie Anm. 8), Bd. 5, S. 257-277, hier: S. 258-261.

20. Zu den Problemen der habsburgischen Verwaltungsorganisation allgemein vgl. Christoph Link, Die habsburgischen Erblande, die böhmischen Länder und Salzburg, in: Kurt G. A. Jeserich, Hans Pohl, Georg-Christoph von Unruh (Hgg.), Deutsche Verwaltungsgeschichte Bd. I: Vom Spätmittelalter bis zum Ende des Reiches, Stuttgart 1983, S. 469-551, hier: S. 473 f., 503f. Vgl. auch Wilhelm Beemelmans, Urkunden zur Geschichte der vorderösterreichischen Behörden in Enzisheim, in: Mitteilungen der Gesellschaft für Erhaltung der geschichtlichen Denkmäler im Elsaß, 2. Folge, 23 (1911), S. 438-524 und ders., Die Organisation der vorderösterreichischen Behörden in Ensisheim im 16. Jahrhundert, in: ZGO, NF 22 (1907), S. 52-92, 627-656; NF 23 (1908), S. 195-220.

21. Vgl. Winfried Schulze, Hausgesetzgebung und Verstaatlichung im Hause Österreich vom Tode Maximilians I. bis zur Pragmatischen Sanktion, in: Helmut Newhaus, Johannes Kunisch (Hgg.), Der dynastische Fürstenstaat. Zur Bedeutung der Sukzessionsordnungen für die Entstehung des frühmodernen Staates, Berlin 1982, S. 252271, passim, bes. S. 259 f., 264.

22. Hirn, Erzherzog Ferdinand (wie Anm. 19), Bd. 2, S.71. 
darum handelte es sich zunächst ${ }^{23}$, als katholische Reformpolitik betrieben werden konnte. Herrschaftliches Handeln folgte dabei allerdings notwendig der ihm durch die eigene Struktur vorgegebenen Rationalität. Da Herrschaft sich noch in erster Linie als Addition von Besitz- und Rechtstiteln darstellte und nicht als institutionelles Arrangement, agierte sie auch entsprechend. Analog nahm sich die Kirche aus Sicht der Dynastie, die sich hier in nichts von der anderer Adelsfamilien unterschied, in der Mitte des 16. Jahrhunderts noch kaum als festgefügte Institution mit einem in Rechtsform gegossenen Handlungsrahmen aus, sondern als Agglomeration von frei verfügbaren und deswegen auch frei kombinierbaren Besitzrechten und Pfründen. Staatlicher und kirchlicher Raum ließen sich hier nicht unterscheiden. Entsprechend ist ein Bruch mit dieser Grundstruktur immer dann zu verzeichnen, wenn die je eigene Handlungsrationalität von Staatlichkeit und Kirche auseinandergehalten und auch als trennend behandelt wurde.

Es läßt sich nun sehr genau beobachten, wie im Prozeß der konfessionellen Festigung und Reform diese Differenz immer genauer beachtet wurde. Kardinal Andreas und Leopold von Tirol stehen an vorderster Stelle für diese Entwicklung. Ihre Karrieren waren zunächst der Versuch, dynastische Versorgungsnotwendigkeiten mit einer als Territorialpolitik verstandenen Kirchenpolitik zu verbinden. Andreas, aus der unstandesgemäßen Ehe Ferdinands mit Philipine Welser, 1576 mit der Kardinalswürde ausgezeichnet, wurde 1579 als Gubernator aller ober- und vorderösterreichischen Lande installiert. Parallel lief die Ausgestaltung seiner geistlichen Karriere: Mit der Koadjutorie in Brixen von 1580 wurde die Übernahme der Bischofswürde 1589 vorbereitet. Um seine Ausstattung zu verbessern, erhielt er 1587 die Abteien Murbach und Lüders. ${ }^{24}$ In dasselbe Jahr datiert der Versuch, ihm auch die Abtei Weingarten zukommen zu lassen. ${ }^{25}$ Trotz seiner festen Verankerung in der Herrschaftsmechanik der Habsburger und wiewohl er auch nach Amtsübernahme weiterhin in Ensisheim residierte ${ }^{26}$, wechselte er mit der Übernahme des Konstanzer Bischofsamtes die Seiten. Er wurde zu einem ernsthaften Ver-

23. Ich folge hier der These von Dietmar Willoweit, Katholischer Konfessionalismus als politisches und rechtliches Ordnungssystem, in: Reinhard, Schilling (Hgg.), Katholische Konfessionalisierung (wie Anm. 5), S. 228-241, bes. S. 232 f.

24. Stievermann, Vorlande (wie Anm. 19), S. 269.

25. Rudolf Reinhardt, Restauration, Visitation, Inspiration. Die Reformbestrebungen in der Benediktinerabtei Weingarten von 1567-1627, Stuttgart 1960, S. 161.

26. Alfred A. Strnad, Markus Sittich von Hohenems und Andreas von Österreich, in: Elmar L. Kuhn, Eva Moser, Rudolf Reinhardt, Petra Sachs (Hgg.), Die Bischöfe von Konstanz, Bd. 1: Geschichte, Friedrichshafen 1988, S. 396-403, S. 403. 
treter des kirchlichen Rechtsstandpunktes, der auch vor offenen Konflikten mit dem Innsbrucker Regiment nicht zurïckschreckte. ${ }^{27}$ Leopold, der Bruder Ferdinands von Innerösterreich, zog die Grenze auf der anderen Seite. Auch er bekleidete bereits seit 1598 in Passau und ab 1607 zusätzlich in Straßburg Bischofswürden; 1618 ernannten Matthias und Ferdinand ihn zum Statthalter Tirols und Vorderösterreichs. 1625 gab er seine geistlichen Ämter auf und unterstrich diesen Wechsel auf die Seite der weltlichen Herrschaft, indem er 1626 aus dem Zölibat in die Ehe mit Claudia von Medici eintrat. ${ }^{28}$

Auf anderen Feldern war der Religionspolitik als Erwerb von Pfründen und Rechten, wie die Habsburger sie betrieben, ein ebenfalls abnehmender Erfolg beschieden. Die „Insassen“ der Markgrafschaft Burgau, deren Reichsstandschaft man auf unterschiedlichen Wegen aufzubrechen suchte, vereinigten sich $1559 \mathrm{zu}$ einem „Engeren Ausschuß", um sich zusammen mit anderen Reichsständen gegen den Zugriff der Innsbrucker Regierung zur Wehr zu setzen. $^{29}$ Besondere Bedrohungen hatte die Abtei Weingarten auszustehen, die durch den von Gerwig Blarer 1531/33 geschlossenen Vertrag zwar zunächst der Gefahr der Landsässigkeit entging, aber weiterhin mehrfach und mit besonderer Intensität in den 1580 er Jahren in die Kastenvogtei des Reichslandvogtes gezwungen werden sollte. Entscheidend in unserem Zusammenhang waren die Argumente in dieser Auseinandersetzung. Ferdinand und sein Reichsvogt beriefen sich auf das Notreformationsrecht eines „eyfrigen catholischen Fürsten, “ dem sich im Falle offenkundiger Mißwirtschaft auch ein geistlicher Reichsstand nicht entziehen könne. ${ }^{30}$ Der Versuch schlug fehl, und man kann im Gegenteil beobachten, wie Weingarten parallel zur Entwicklung anderer oberschwäbischer Klöster seine Gerichtsrechte seit 1608 bis zur Territorialherrschaft ausbaute. ${ }^{31}$ Über seine Selbständigkeit als geistliche Institution wachten Abt und Konvent aufmerksamer als jemals vorher. Um

27. Rudolf Reinhardt, Die Beziehungen von Hochstift und Diözese Konstanz zu Habsburg-Österreich in der Neuzeit. Zugleich ein Beitrag zur archivalischen Erforschung des Problems "Kirche und Staat", Wiesbaden 1966, S.37 f.; Strnad, Markus Sittich (wie Anm.26), S. 402 f.; Georg May, Die deutschen Bischöfe angesichts der Glaubensspaltung des 16. Jahrunderts, Wien 1983, S. 310.

28. Stievermann, Vorlande (wie Anm. 19) S. $273 \mathrm{f}$.

29. Armgard von Reden-Dohna, Zwischen österreichischen Vorlanden und Reich: die Schwäbischen Reichsprälaten, in: Hans Meier, Volker Press (Hgg.), Vorderösterreich in der Frühen Neuzeit, Sigmaringen 1989, S.75-91, hier: S.78f.

30. Reinhardt, Restauration (wie Anm. 25), S. 160.

31. Für Weingarten: Reinhardt, Restauration (wie Anm. 25), S. $173 \mathrm{ff}$; allgemein: Hans-Martin Maurer, Die Ausbildung der Territorialgewalt oberschwäbischer Klöster vom 14. bis zum 17. Jahrhundert, in: BlldtLG 109 (1939), S. 151-191, hier: S. 172-188. 
dem Vogt keine Eingriffsmöglichkeiten bei der Wahl des Nachfolgers zu bieten, resignierte Abt Wegelin 1627 in einer wohlüberlegten Aktion. Im nachfolgenden Schriftwechsel mit der Landvogtei berief man sich auf die „heyligen Canones", welche „clärlich mit sich bringen, wer bei den Electionibus Abbatum $\mathrm{zu}$ admittieren und $\mathrm{zu}$ exkludieren ${ }^{\mathrm{c} 32}$, und unterstrich damit den Anspruch auf einen kirchlichen Rechts- und Handlungsbereich eigener Dignität. Dem werde, selbst bei schwersten Störungen, durch Einmischungen des brachium seculare mehr geschadet als genützt, hatte bereits 1585 ein Dillinger Jesuit an Wegelin geschrieben. ${ }^{33}$

Aus den Auseinandersetzungen um Weingarten geht hervor, daß das Instrument der Kirchenvisitation territoriale Herrschaftsansprüche und Abgrenzung eigener Rechts- und Handlungsbereiche in einer besonders attraktiven Weise vermengte, weil es der geistlichen wie der weltlichen Gewalt mehr als andere Instrumente des Herrschaftsalltages die Gelegenheit bot, raumgreifende Präsenz zu zeigen. Trotzdem gelang es den Bischöfen, auf diesem Feld die Initiative zu behalten und Visitationen zu einer Grenzziehung gegen die staatliche Gewalt zu gestalten. Einzig, wo man sich auf unzweifelbare Aufsichtsrechte über Klostergut berufen konnte, boten Visitationen den landesherrlichen Beamten eine Gelegenheit zum direkten Eingreifen und manchmal auch Anlaß, ein Stift in weltliche Verwaltung zu ziehen. ${ }^{34}$ Eine besondere Situation entstand zu Beginn der 1570er Jahre, als Ferdinands Räte von einer Zunahme des protestantischen und wiedertäuferischen Sektenwesens insbesondere unter den Bergleuten Tirols und Vorarlbergs berichten mußten. Ferdinand forderte daraufhin zwar die Bischöfe mehrmals zu Visitationen auf ${ }^{35}$, ordnete aber offenbar gleichzeitig selbst entsprechende Maßnahmen an, die keinen unmittelbaren Übergriff in die geistliche Rechtssphäre darstellten: von 1570 an visi-

32. Reinhardt, Restauration (wie Anm. 25), S. $166 \mathrm{f}$.

33. Ebd., S. 167 Anm. 143: Es geht um die Möglichkeit, den in Verruf gekommenen Abt Raittner abzusetzen. Der Jesuit schreibt: „Si Abbas vi et brachii secularis ope depositionem suam impedire velit, dua gravissima incommoda incurrent, alterum quod executionem Ordinarii et Ecclesiasticae potestate ope impedire odiosissimum est, et iure communi tum Concilii Tridentini veteri valde adversum, ut qui ita impediunt, in gravissimas poenas incedere possint, tanquam violatores ecclesiasticae libertatis et perturbatores..."

34. Stievermann, Vorlande (wie Anm. 19), S. $267 \mathrm{f}$.

35. Bilgeri, Vorarlberg (wie Anm. 18), S 121: Wegen der sektischen Lehre wird der Bischof von Konstanz 1572 zu einer Visitation aufgefordert. Franz Gfrörer, Die katholische Kirche im österreichischen Elsaß unter Erzherzog Ferdinand II., in: Zs. f. die Gesch. des Oberrheins, NF 10 (1895) S. 481-523, hier: S. 503: 1570 schreibt Ferdinand in dieser Angelegenheit bereits an alle Bischöfe. 
tierten landesherrliche Beamte zunächst in Tirol und im Jahr 1580/81 dann auch in Vorarlberg den Buchbesitz in den der Häresie verdächtigen Gemeinden. ${ }^{36}$ Hier fand die Landesherrschaft ein neues Betätigungsfeld, das durch die rasante Entwicklung des Buchdruckes entstanden war und für das es deswegen auf dem weitgehend durch das Herkommen umrissenen forum mixtum noch keinen eindeutigen Ort gab. Ferdinand hatte seinen Räten die entsprechende Argumentation bereits mitgeteilt: weil die geistliche Obrigkeit beim gemeinen Mann so wenig auszurichten in der Lage sei, könne ein Vergehen gegen die Kirche sich von einem crimen ecclesiasticum zu einem crimen mixtum wandeln, das dann nach dem weltlichen Schwert verlange. Ansonsten wirkten weltliche Beamte im Bistum Konstanz nur in der allgemeinen Visitation von 1573 mit, wobei die bischöflichen Behörden und das Domkapitel eifersüchtig und mit Erfolg darüber wachten, daß den landesherrlichen Beamten allenfalls Beobachterstatus und hier wiederum nur bei Klöstern zukam. ${ }^{37}$

Ein letzter, in Besitzrechten begründeter, allerdings beschränkter Bereich landesherrlicher Gestaltungsmöglichkeiten fand sich im Pfründenpatronat. ${ }^{38}$ Die Vergabe orientierte sich allerdings weniger am seelsorgerlichen Bedarf oder auch an der geistlichen Eignung der Kandidaten, sondern die Pfründen wurden als Fundus der landesherrlichen Versorgungs- und Klientelpolitik genutzt. $^{39}$

36. Him, Erzherzog Ferdinand (wie Anm. 19), S. 183-190; Bilgeri, Vorarlberg (wie Anm. 18), S.127; im Detail vgl. Péter Ötvös, Büchervisitation in einem katholischen Lande. Das Beispiel Tirol, in: Jósef Jankovics, S. Katalin Németh (Hgg.), Freiheitsstufen der Literaturverbreitung. Zensurfragen, verbotene und verfolgte Bücher, Wiesbaden 1998, S. 83-103.

37. August Kluckhohn, Urkundliche Beiträge zur Geschichte der kirchlichen Zustände, insbesondere des sittlichen Lebens der katholischen Geistlichen in der Diöcese Konstanz während des 16. Jahrhunderts, in: Zs. f. KiG. 16 (1896), S. 590-625, hier: S. 607 ff., 620 f.; Gmehlin, Aus Visitationsprotokollen der Diözese Konstanz 15711786. Ein Beitrag zur Geschichte des Klerus, in: ZGO 25 (1873), S. 129-204, hier: S. 130-145. Zusammenfassend zur Anordnung und Durchführung der Visitationen vgl. Hans-Wilhelm Rohde, Evangelische Bewegung und katholische Restauration im österreichischen Breisgau unter Ferdinand I. und Ferdinand II. 1521-1595. Studien zur Kirchenpolitik der Habsburger in Vorderösterreich im 16. Jahrhundert, Diss. phil. (masch.), Freiburg 1957, S. 104 ff., 118 ff., 121, 148 ff., 152-160.

38. Wolfgang Müller, Die kirchlichen Verhältnisse, in: Fritz Metz (Hg.), Vorderösterreich. Eine geschichtliche Landeskunde, 2. Aufl., Freiburg 1976, S. 225-248, hier: S. 225: Im Breisgau waren nur 7\% der Kirchenpfründen landesherrlich; 13\% lagen im Zugriff des Ortsadels und die restlichen drei Viertel bei den Klöstern und Stiften.

39. Bilgeri, Vorarlberg (wie Anm. 18), S. 122; für Tirol vgl. Jïrgen Bïcking, Frühab- 
Je genauer die Grenzen zwischen weltlicher und geistlicher Sphäre konturiert wurden, desto prekärer wurde naturgemäß die Rechtsstellung der Geistlichkeit und überhaupt die Abgrenzung der Rechtsbereiche. In der Frage der Steuerpflicht der Geistlichkeit, an der territorialer Herrschaft in besonderem Maß gelegen sein mußte, konnte die Landesherrschaft in den Vorlanden ihre Interessen weitgehend behaupten. Die Geistlichkeit trug ihren - allerdings von den Ordinarien erhobenen - Teil der Türkensteuer und wurde immer wieder auch zu Landsteuern herangezogen. ${ }^{40}$ Sie wurde hier in den sich ausformenden fiskalischen Untertanenverband integriert. Es gelang allerdings nicht, die Geistlichkeit in die weltliche Gerichtsbarkeit zu ziehen. Auch in Kriminalsachen blieb der Ordinarius zuständig. Innsbruck achtete streng darauf, daß seine Behörden allenfalls Amtshilfe leisteten. ${ }^{41}$ Umstrittener war wiederum die Inventarisierung des Klerikernachlasses, da hier die landesherrliche Seite ihre Vogteirechte ins Feld führen konnte. Im Konkordat zwischen Konstanz und Innsbruck von 1629 einigte man sich schließlich mehr auf einen Formelkompromiß als auf eine handhabbare Praxis: wer vor Ort sei, solle inventarisieren. ${ }^{42}$ Bestehen und unangefochten blieb im 16. und 17. Jahrhundert ebenfalls die bischöfliche Gerichtsbarkeit über Laien in Ehe- und Schuldsachen, wie sie im Konkordat von 1498 festgehalten worden war. ${ }^{43}$

Auf allen Feldern zeigte sich die wachsende Inkompatibilität zwischen den unterschiedlichen Handlungsrationalitäten im kirchlichen und im weltlichen Bereich und den daraus sich ergebenden differenten Modi, eigene Interessen zu formulieren. Verbunden blieben beide Segmente der Gesellschaft durch den Umstand, daß Rechte und Besitztitel in beiden Fällen das Fundament institutioneller Zusammenhänge abgaben. Darüber aber entfalteten sich im Prozeß der Konfessionalisierung in beiden Bereichen Rationalitäten eigener Art, die wiederum darin kongenial waren, daß sie die Ordnung einer Adelsgesellschaft in Frage stellten und nach und nach veränderten.

Wenn die Spielräume in der landesherrlichen Kirchenpolitik nach 1560 dem Eindruck nach eng begrenzt blieben, so eröffnete der Impuls der katholischen Reform in der Bestimmung und Formung der Glaubenspraxis bei den Untertanen ein sehr viel breiteres und offeneres Feld. Ferdinand war hier von der

solutismus und Kirchenregiment in Tirol (1565-1665). Ein Beitrag zum Ringen zwischen ,Staat' und ,Kirche' in der Frühen Neuzeit, Wiesbaden 1972, S.70.

40. Reinhardt, Beziehungen (wie Anm. 27), S. 276-281.

41. Ebd., S. $287 \mathrm{f}$.

42. Ebd., S. 262 f.; der Text der Vereinbarung ebd., S. 326.

43. Ebd., S. 289; Text von 1498 ebd., S. 317 f. 
Überzeugung geleitet, daß „kein strenger oder fester band, so die menschenherzen zusammenhaltet, nit ist, als die einigkeit in der religion." Die Zugeständnisse seiner Brüder in den anderen Ländern der österreichischen Krone an die Stände zeigten genugsam, daß daraus nur "nachteil und unrat “ erwachse. $^{44}$

Diese Äußerung zeugt von einem sehr sicheren Gespür für die politischen und strukturellen Konsequenzen des landesfürstlichen jus reformandi. Religionsfragen waren immer politische Fragen und sie betrafen sofort den Kern des Staatsbildungsprozesses: Einordnung eines Selbständigkeit beanspruchenden Adels in einen sich ausformenden neuen institutionellen und rechtlichen Rahmen, in dem Macht konzentriert war und Politik mit dem Anspruch auftrat, für die Gesamtheit der Menschen in einem Herrschaftsgebiet verbindliche Entscheidungen zu treffen.

Die landständische Ritterschaft in den engeren Vorlanden hatte bis zur Mitte des Jahrhunderts kaum Interesse für die neue Lehre gezeigt. Erst in den 1570er Jahren bekannten sich eine Reihe von Adelsfamilien zu ihr, holten evangelische Prediger an ihre Sitze, handelten offen nach den evangelischen Frömmigkeitskonventionen - oder mißachteten zumindest einige katholische, die jetzt zum Distinktionskriterium wurden -, überließen ihre Verwaltung evangelischen Amtsleuten und sorgten gelegentlich auch dafür, daß ihren Untertanen nach dem Evangelium gepredigt wurde. ${ }^{45}$ Besonders hervor taten sich dabei die von Tübingen, die Rappoldsteiner und mit einem prononcierten Hang zur Irenik auch die von Schwendi ${ }^{46}$, aber insgesamt betraf das Problem weit mehr Adelsfamilien. Im Ritterschaftsausschuß der vorländischen Landschaft waren um 1600 Protestanten und Katholiken gleich stark. ${ }^{47}$ Ferdinand und seine Räte in Innsbruck wie in Ensisheim wußten, daß es sich um eine politische Machtfrage handelte. Das kam schon in der generellen Weigerung zum Ausdruck, die Beschlüsse des Tridentinums in den ständischen Versammlungen der Vorlande überhaupt beraten zu lassen. ${ }^{48}$ Jetzt formulierten

44. Hirn, Erzherzog Ferdinand (wie Anm. 19), S.162f. (1570); vgl. zum Gesamtproblem Klaus Schreiner, Rechtgläubigkeit als „Band der Gesellschaft“ und „Grundlage des Staates". Zur eidlichen Verpflichtung von Staats- und Kirchendienern auf die "Formula Concordiae" und das „Konkordienbuch", in: Martin Brecht, Rudolf Schwarz (Hgg.), Bekenntnis und Einheit der Kirche. Studien zum Konkordienbuch, Stuttgart 1980, S. 351-380, hier: S. 352-370.

45. Speck-Nagel, Landstände (wie Anm. 17), S. 428 ff.

46. Ebd., S. 431-434.

47. Ebd., S. 447 f.; zu den Familien im einzelnen S. 435.

48. Hirn, Erzherzog Ferdinand (wie Anm. 19), S. 163. 
es die Gutachten noch deutlicher: der Landesherr dürfe von seinem jus reformandi hier nicht Gebrauch machen, denn schreite man zur Durchsetzung der Religionsmandate, so sei zu befürchten, daß die Betroffenen „sich villeicht nit außtreiben lassen, darinnenn zuesammen verbinden, bei den sectischen benachparten schuz und schirm suochen ...". Kanzler Moser, der dies 1575 schrieb, beschwor eindringlich die Gefahr, daß „e[uer] f[ürstlic]h d[urc]h[lauch]t gehorsamen stend" iiber neue Religionsmandate oder Exekution der alten zu „ungehorsame und abfahl" bewogen würden. ${ }^{49}$ Während der gelehrte Kanzler zum Abwarten riet, skizzierte der adelige Landvogt Graf Zollern eine Lösung, die ziemlich genau die Mechanik des Adelskompromisses im absolutistischen Territorialstaat ${ }^{50}$ vorwegnahm: Man müsse am Hof genügend attraktive Provisionsstellen schaffen, und gleichzeitig durch nachhaltige Verbesserungen im Erziehungswesen dafür sorgen, daß der Adelsnachwuchs sich für diese katholischen Hofkarrieren qualifizieren könne. Konkret schlug er vor, ein Elitekavallerieregiment aufzustellen, das nebenbei noch die Landesdefension entscheidend heben könne. ${ }^{51}$

Das Kavallerieregiment wurde nicht aufgestellt, aber mit der in Ensisheim von Johann Rasser geführten, seit 1576 durch Regierungszuschüsse abgesicherten katholischen Internatsschule ${ }^{52}$ sowie dem 1604 in Konstanz eingerichteten Jesuitengymnasium ${ }^{53}$ entstand im Verbund mit den neu gegründeten oder jesuitisch reformierten Universitäten in Molsheim, Dôle, Dillingen und Freiburg sowie schließlich der Benediktineruniversität Salzburg eine katholische Bildungslandschaft ${ }^{54}$, die dem Adel des Südwestens jene Bedingungen

49. Speck-Nagel, Landstände (wie Anm. 17), S. 436.

50. Die gegenwärtige Diskussionslage zu Begriff und Struktur des absoluten Staates ist dokumentiert in Ronald G. Asch, Heinz Duchhardt (Hgg.), Der Absolutismus - ein Mythos? Strukturwandel monarchischer Herrschaft in West- und Mitteleuropa (ca. 1550-1700), Köln usw. 1996; vgl. darin insbes. Nicholas Henschall, Early Modern Absolutism 1500-1700: Political Reality or Propaganda?, S. 25-53, hier: S.35-41. Am Beispiel Bayerns sind die Zusammenhänge herausgearbeitet von Rudolf Schlögl, Absolutismus im 17. Jahrhundert. Bayerischer Adel zwischen Disziplinierung und Integration. Das Beispiel der Entschuldungspolitik nach dem Dreißigjährigen Krieg, in: ZhF 15 (1988), S.151-187.

51. Speck-Nagel, Landstände (wie Anm.17), S. $438 \mathrm{f}$.

52. Ebd., S. $440 \mathrm{f}$.

53. Konstantin Holl, Fürstbischof Jakob Fugger von Konstanz (1604-1626) und die Katholische Reform der Diözese im ersten Viertel des 17. Jahrhunderts, Freiburg 1898, S. $94 \mathrm{ff}$.

54. Vgl. Anton Schindling, Die katholische Bildungsreform zwischen Humanismus und Barock. Dillingen, Dohle, Freiburg, Molsheim und Salzburg: Die Vorlande und die benachbarten Universitäten, in: Maier, Press (Hgg.), Vorderösterreich (wie 
bot, von denen Graf Zollern gesprochen hatte. Die begleitenden positiven Anreize bestanden in einer Mischung aus Sanktionen und Verhaltensmaßregeln: Verboten wurde dem Adelsnachwuchs das Studium an protestantischen Universitäten ${ }^{55}$, Adeligen aus protestantisierenden Häusern bestellte man wie im Falle Rappoldstein katholische Vormünder ${ }^{56}$ und bei der Vergabe von Stellen in Hof und Verwaltung setzte sich das Prinzip der ausschließlichen Katholizität durch, das Ferdinand selbst anfangs noch großzügig mißachtet hatte. ${ }^{57}$

Diese Konstellation schuf die Voraussetzungen dafür, daß die Konfrontation sich in den nachfolgenden zwei Jahrzehnten schließlich doch entzerrte. 1586 zeigte sich allerdings nochmals, was auf dem Spiel stand. Auf einen erneuten Anlauf Ferdinands, den Adel persönlich und in der Verwaltung seiner Besitzungen zur Katholizität zu zwingen, reagierte die Ritterschaft mit einem Gutachten, das umgekehrt das jus reformandi auch für die Adeligen in Anspruch nahm und in der Frage der Landsässigkeit keinesfalls ein Unterordnungsverhältnis anerkennen wollte, sondern sie als bloßes Lehens- und Dienstverhältnis verstand. Auch diesmal wich die Landesherrschaft zurück. Im Gegenzug begnügte die Ritterschaft sich mit dem exercitium privatum und hielt im Regelfall ihre Untertanen zur Katholizität an. ${ }^{58}$ Selbst der offenkundig protestantische Herr von Rappoldstein untersagte seinen Hintersassen den Fleischverzehr an Fasttagen. ${ }^{59}$ Eine starke Stellung war dem vorländischen Adel aber geblieben. Sie war nicht weit von der Position der Reichsritterschaft entfernt.

Um so intensiver bekümmerte die Landesherrschaft sich um die Bevölkerung in den Städten und Dörfern. ${ }^{60}$ Über sie ergoß sich seit den 1570 er Jahren

Anm. 29), S. 137-176. In Molsheim vgl. Josef Schmidlin, Die religiös-kulturelle Hebung des katholischen Volkes im Elsass am Vorabend des Dreißigjährigen Krieges, in: Archives de l'Eglise d'Alsace, NF 3 (1949/50), S.129-181, bes. S. $130 \mathrm{ff}$.

55. Solche Verbote wurden bereits 1539 und 1549 ausgesprochen: Speck-Nagel, Landstände (wie Anm. 17), S. 440.

56. Ebd., S. 442.

57. Hirn, Erzherzog Ferdinand (wie Anm. 19), S. 194f.; zum Beamteneid als Glaubensbekenntnis siehe ebd., S. 168.

58. Speck-Nagel, Landstände (wie Anm. 17), S. 443-448.

59. Ebd.,. S. 448.

60. 1573 schreibt Erzherzog Ferdinand an die Regierung Ensisheim über das sektische Wesen, man könne es leider nicht auf einen Schlag ausrotten, da es viele Anhänger hohen und niedrigen Standes gefunden habe. Deswegen müsse man mit „beschaidenheit" dagegen vorgehen und bei den „gemainen personen" den Anfang machen. Gfrörer, Katholische Kirche (wie Anm. 35), S. 511. 
eine wahre Flut von Religionsmandaten ${ }^{61}$, an der die ältere Forschung meist den katholischen Glaubenseifer der Landesfürsten und die jüngere deren Willen zur Sozialdisziplinierung abgelesen hat. Wichtiger als Motivlagen, die weder den Akteuren eindeutig vor Augen gestanden haben dürften und erst recht nicht für Historiker definitiv zu klären sind, scheinen die strukturellen Folgen dieser Maßnahmen. Unabhängig von ihrer Wirksamkeit gaben sie Gelegenheit zur spürbaren Verdichtung landesherrlicher Präsenz. Dies konnte auf die Untertanen zielen, mindestens ebenso wichtig war jedoch - nicht nur in der Situation Vorderösterreichs - die Durchdringung des Amtsapparats. Die Frage der Katholizität eröffnete breite Pfade, auf denen der Herrschaftswille des Landesherrn in Gestalt von Polizeiordnungen, Mandaten und schließlich auch Sanktionsmaßnahmen den Untertanen und Amtsträgern vor Augen trat. Politische Integration, die nicht nur mediate Herrschaftsträger, sondern „Untertanen" zu erfassen suchte, mußte Raumwirkung entfalten, und angesichts der verfügbaren Kommunikationsmedien sowie der institutionellen Fragilität des Amtsapparats waren andere „Öffentlichkeiten der Macht, “ die dies bewerkstelligten, noch kaum zu erzeugen. ${ }^{62}$

Für diesen Zweck eignete sich ein Diskurs, der Unterscheidungen traf und auf Gebot und Verbot abstellte, besser als alle anderen. Deswegen konnte Herrschaft sich auch auf die Differenzierung der Glaubensrichtungen einlassen und trotz des „unraths", der daraus entstand, sich an der Unterscheidungsarbeit beteiligen. Diese Notwendigkeit der Abgrenzung verlieh sichtbaren Äußerungen der Frömmigkeit eine Bedeutung, die sich theologisch häufig nur schwer begründen ließ, wenngleich es natürlich auch immer die in den Symbolen der Evangelischen und zwischenzeitlich auch des Tridentinums

61. Sie sind in unterschiedlicher Detailgenauigkeit aufgeführt bei Rohde, Evangelische Bewegung (wie Anm.37), S.134 ff.; Hirm, Erzherzog Ferdinand (wie Anm. 19), S. $170 \mathrm{ff}$; ders., Erzherzog Maximilian der Deutschmeister. Legend von Tirol, Bd.1, hg. mit einem Nachwort von Heinrich Noflatscher, Innsbruck 1915, S. 251 f.; Bilgeri, Vorarlberg (wie Anm. 18), S.122f.

62. Die Erforschung frühmoderner Öffentlichkeiten steckt durch die lange Dominanz der Thesen von Jïrgen Habermas immer noch in den Anfängen. Vgl. jetzt Harry Oelke, Die Konfessionsbildung des 16. Jahrhunderts im Spiegel illustrierter Flugblätter, Berlin usw. 1992, bes. S. 95 ff., $136 \mathrm{ff.}$, sowie zum 16. Jahrhundert siehe jetzt Esther-Beate Körber, Öffentlichkeiten in der Frühen Neuzeit. Teilnehmer, Formen und Institutionen öffentlicher Kommunikation im Herzogtum Preußen 1525-1618, Berlin usw. 1998; für das 18. Jahrhundert siehe Andreas Gestrich, Absolutismus und Öffentlichkeit. Politische Kommunikation in Deutschland am Beginn des 18. Jahrhunderts, Göttingen 1994, bes. S. 34-74. 
aufgebaute dogmatische Differenz war, die sich hüben wie drüben einen sichtbaren Ausdruck suchte. ${ }^{63}$

Daß die regelmäßige Feier der Messe in den Pfarrgemeinden, die feierliche Gestaltung der Gottesdienste und die regelmäßige, vor allem aber würdige Teilnahme der Gläubigen in den Religionsmandaten immer wieder angemahnt wurde, zog eine Grenze zum bloßen Predigtgottesdienst der Protestanten. Noch deutlicher traten die dogmatischen Unterschiede beim Verbot der Kommunion in beiderlei Gestalt hervor, wenngleich hier selbst die Kirche bis ins 17. Jahrhundert hinein mit Zweideutigkeiten in der liturgischen Praxis zu kämpfen hatte. ${ }^{64}$ Von einer Überwachung der Beicht- und Kommunionsfrequenz durch entsprechende Listen, wie sie in Tirol initiiert wurden ${ }^{65}$, ist für die Vorlande nichts berichtet, aber das Beispiel macht deutlich, daß man jede Gelegenheit bereitwillig ergriff, Untertanen wie Klerus mit dem Netz einer sich bürokratisierenden Verwaltung zu überwerfen.

Nur noch vermittelt ließ sich die theologische Substanz aber im Fleischverbot an Fasttagen erkennen, das, wenn man die Zahl der Mandate rechnet, seit den 1570 er Jahren aber zu den wichtigsten Bestandteilen der katholischen Glaubenspraxis aufrückte. ${ }^{66}$ Seine Karriere dürfte daher weniger darauf zurückzuführen sein, daß es sich mit dem Opfercharakter der Messe in Zusammenhang bringen ließ, sondern mit dem Umstand, daß bereits Reformatoren wie Zwingli ihren Dissens durch demonstratives Fleischessen dokumentiert hatten. Die Übertretung des Fastengebotes ${ }^{67}$, Arbeit an einem der vielen Hei-

63. Eindrückliche Belege für diesen Zusammenhang bei Frauke Volkland, Konfessionelle Grenzen zwischen Auflösung und Verhärtung. Bikonfessionelle Gemeinden in der Gemeinen Vogtei Thurgau (CH) des 17. Jahrhunderts, in: Hist. Anthropologie. Kultur, Gesellschaft, Alltag 5 (1997), S. 370-387, bes. $383 \mathrm{ff}$.

64. Von 1565-1584 ergeht dazu ein Mandat in höchstens zweijährigem Abstand: Hirn, Erzherzog Ferdinand (wie Anm. 19), S. 170. Auf der Konstanzer Synode von 1609 hielt man es noch für nötig, die Gläubigen darüber aufzuklären, daß der Usus der Ratselite und der Geistlichkeit, nach der Kommunion einen Schluck Wein zu trinken, nichts mit Verabreichung des Leibes Christi in beiderlei Gestalt zu tun habe; vgl. Holl, Fürstbischof Jakob Fugger (wie Anm.53), S.110f.; der Text der Synodalverhandlungen in Synodus Constantiensis Dioecesana. Anno Christi MDCIX Pauli V. PP. V. Rudolphi II. Imp. XXXIII. Sub Jacobo Fuggero Epiocopo Constantiensi undevicesimo Mensis Octobris die celebrata, in: Johann Friedrich Schaunat, Joseph Hartzheim, Hermann Scholl (Hgg.), Concilia germaniae, Bd.7, Köln 1769, S. 857 f. (Pars I, Tit. VIII, Cap. X).

65. Hirn, Erzherzog Ferdinand (wie Anm. 19), S. 176.

66. Ebd., S. 170.

67. Bilgeri, Vorarlberg (wie Anm. 18), S. 172. 
ligenfeste ${ }^{68}$ und schließlich sogar die Mißachtung des 1583 eingeführten Gregorianischen Kalenders ${ }^{69}$ wurden zu Indizien häretischer Gesinnung und zogen seit den 1580er Jahren in allen Teilen der habsburgischen Vorlande entsprechende obrigkeitliche Untersuchungen und Sanktionen nach sich.

Die Förderung von Prozessionen wies bereits in eine andere Richtung. Seit dem vorletzten Jahrzehnt des Jahrhunderts erließen die Landesherren in Zeiten dringender Not immer häufiger Aufrufe zum öffentlichen, gemeinsamen $\mathrm{Gebet}^{70}$, so daß die daraufhin in den Gemeinden angesetzten 40stündigen Gebete zur sinnfälligen Verdeutlichung des herrscherlichen Gottesgnadentums und der daraus ableitbaren Fürsorge- und Leitungspflichten wurden. Gegen Ende des Jahrhunderts traten die Habsburger immer häufiger als Stifter von großen Jahrtagen an besonderen Heiligenfesten auf. ${ }^{71}$ Dies war der Ansatzpunkt für die künftige Vermischung von öffentlicher Frömmigkeitsübung und prachtvoller öffentlicher Herrscherinszenierung, die den barocken Herrscherkult der Pietas austriaca schließlich auszeichnete. ${ }^{72}$

All dies war begleitet von eindringlichen Verboten der „religiösen Neuerung, "von Zwangsmaßnahmen gegen diejenigen, die der "sectischen“ Abweichung verdächtig waren, und von Versuchen, die Ausbreitung protestantischer Gedanken durch Zensur und Büchervisitationen ${ }^{73}$, aber auch Beaufsichtigung von Wanderarbeitern zu unterbinden. Ziel war die konfessionelle Homogenität, wobei allerdings weiterhin - wie im Falle des vorländischen Adels - Gesichtspunkte der politischen Opportunität und immer wieder auch der ökonomischen durchaus beachtet und entsprechende Ausnahmen zugelassen wurden. ${ }^{74}$

Man muß die Ernsthaftigkeit katholischer Überzeugungen bei den habsburgischen Landesherren der Vorlande in der zweiten Hälfte des 16. Jahrhunderts nicht bestreiten, um zu erkennen, daß ihr konfessionelles Engagement Gelegenheit gab, Herrschaft nicht nur zu intensivieren, sondern sie auch in

68. Gfrörer, Katholische Kirche (wie Anm. 35), S. 513.

69. Him, Erzherzog Ferdinand (wie Anm. 19), S. 460.

70. Ebd., S. 173 f.

71. Reinhardt, Beziehungen (wie Anm.27), S. 300 f.; Reden-Dohna, Reichsprälaten (wie Anm. 29), S.79.

72. Anna Coreth, Pietas austriaca. Ursprung und Entwicklung barocker Frömmigkeit in Österreich, Wien 1959.

73. Bilgeri, Vorarlberg (wie Anm.18), S.125ff.; Gfrörer, Katholische Kirche (wie Anm. 35), S. $512 \mathrm{f}$,

74. Zu den Rücksichtnahmen in den Bergwerksgebieten und aus anderen gewerblichen Interessen vgl. Hirn, Erzherzog Ferdinand (wie Anm. 19), S. $196 \mathrm{ff}$. 
eine neue Ordnung zu bringen. Landesherrschaft suchte sich auch auf diesem Wege aus den Beschränkungen herauszuarbeiten, die ihr die Macht autonomer Herrschaftsträger auferlegte, indem sie diese neutralisierte oder sie überspielte. Die Sorge für das Seelenheil der Untertanen rechtfertigte den direkten Zugriff und eröffnete ein breites Betätigungsfeld. Dabei wird schon an dieser Stelle erkennbar, daß die Handlungsrationalitäten im staatlichen und kirchlichen Bereich nicht nur gegeneinander gerichtet sind, sondern dann auseinandertreten, wenn sie sich nicht mehr auf Besitz- und Herrschaftsrechte beziehen, sondern einen jeweils institutionell gefestigten und normativ umschriebenen Bezug gewinnen. Herrschaft kann sich in dem Maß zur Staatlichkeit integrieren, indem sich in ihr ein neues Strukturbildungsmuster realisiert.

\section{KIRCHE UND KONFESSION}

Wenn wir uns der römischen Kirche im Konfessionalisierungsprozeß zuwenden, so entfaltet die These, sie sei im Grunde dieselbe geblieben, ${ }^{75}$ allein schon deswegen keine Plausibilität, weil sich die Rahmenbedingungen für die Institution wie für das Glaubensleben im Verlauf des 16. Jahrhunderts dramatisch veränderten. Die Kirche war in einem fundamentalen Sinne als Adelskirche mit der hierarchisch-feudalen Grundstruktur der Gesellschaft verflochten und mußte deswegen auf zwei Ebenen auf die fortschreitende Integration staatlicher Macht, die sich gegen die Adelsgesellschaft entfaltete, reagieren: Sie mußte sich als eigenständiger Handlungs- und Rechtsbereich in einem Gesellschaftsraum behaupten, der zunehmend von institutionalisierter, normativ gefestigter staatlicher Macht durchsetzt wurde, und sie mußte - um der eigenen institutionellen Integration willen - versuchen, die Strukturen der Adelskirche umzubauen oder wenigstens zu neutralisieren, indem sie das Pfründenund Eigenkirchenwesen selbst ebenfalls in einen bürokratisierten Funktionszusammenhang einschmolz. Drittens aber war da die Herausforderung der „sectischen lehren“ in Theologie und Glaubenspraxis, die sich weder durch Gewalt noch durch Ignorieren aus der Welt schaffen ließ. Sie entfalteten ihren verändernden Impuls, wie die Vorlande zeigen, auch dort, wo der Protestantismus in seinen verschiedenen Varianten nach der Mitte des 16. Jahrhunderts nur lokal begrenzt praktiziert wurde. Dies erforderte, auch das kirchliche Leben der neuen Situation anzupassen.

Es kennzeichnet die Besonderheit der historischen Situation, daß die Entwicklungen auf diesen drei Ebenen sich wechselseitig beförderten und ver-

75. S. oben Anm. 8. 
stärkten, so daß Strukturbildungsvorgänge ganz unterschiedlicher Verlaufsrichtung in einem sich selbst stabilisierenden, emergenten Prozeß zusammenflossen, der aus der Konfessionalisierung einen wesentlichen Impuls erhielt, aber in seiner Wirkung weit darüber hinaus griff.

Die Abgrenzung eines autonomen kirchlichen Handlungs- und Rechtsbereiches blieb ein schwieriges Unterfangen angesichts der Tatsache, daß hier auf einem Feld zu handeln war, dessen Formung man der wie auch immer verfaßten weltlichen Macht überlassen mußte, um im Gegenzug einen sozialen Raum eigener Kompetenz und Rationalität behaupten zu können. Die Kirche des 16. Jahrhunderts konnte das brachium seculare allenfalls noch leihweise in Anspruch nehmen. Trotzdem handelten die Bischöfe ab der Mitte des Jahrhunderts gegenüber den Fürsten nicht mehr allein aus der Defensive. Durch das Tridentinum hatte das Kanonische Recht eine Aufwertung und auch Neuprägung erfahren, so daß es jetzt gegen die Ansprüche der weltlichen Seite ins Feld geführt werden konnte. Ob es sich um die rigide Herrschaftspraxis adeliger Patronats- und Eigenkirchenherren handelte, die Ansprüche auf Kontrolle und Mitsprache in der Verwaltung der Temporalien, die der Landvogt gegenüber den Reichsklöstern geltend machte, oder um den landesherrlichen Wunsch, an Visitationen mitzuwirken, Bischof und Theologen waren unter Verweis auf die Canones in der Lage, diese Praxis als durch das Recht nicht gedeckte Übergriffe zu brandmarken. Den Konstanzer Bischöfen wie ihren Amtsbrüdern kam dabei zu Hilfe, daß die Canones einerseits als kodifiziertes Recht an der universalen Unteilbarkeit der Rechtsregeln partizipierten, andererseits aber doch einen dem Inhalt und den Prinzipien nach eigenständigen Rechtsbereich umschrieben. ${ }^{76}$ Es war den Zeitgenossen eine Selbstverständlichkeit, das Recht in Jurisdiktionsbereiche einzelner Macht- und Herrschaftsträger zu segmentieren. Aus dieser Situation heraus lag es für die Bischöfe nahe, den Verrechtlichungsprozeß im Verhältnis von kirchlicher und weltlicher Sphäre voranzutreiben, gerade um den Canones einen Freiraum zu schaffen, obwohl doch Recht und Macht auf der anderen Seite lagen. Entsprechende Verträge wurden von Kardinal Andreas bereits 1592/93 mit dem

76. Das Problem wird sichtbar, wenn man sich vor Augen hält, daß moderne Gesellschaften die Universalität und Generalisierbarkeit des Rechtes umgesetzt haben. Auch rechtliche Sonderbezirke, wie sie Korporationen etwa gestattet werden, müssen den Grundprinzipien des Bürgerlichen Gesetzbuches folgen. Für Ausnahmen gibt es dann ein Vereinsrecht. Vgl. allgemein dazu: Niklas Luhmann, Das Recht der Gesellschaft, Frankfurt am Main 1995, S. 136, 260-275; Art. Kirchenrecht, katholisches, in: Adalbert Erler, Ekkehard Kaufmann (Hgg.), HRG 2, Berlin 1978, Sp.771-775. 
Schwäbischen Reichsgrafenkollegium geschlossen ${ }^{77}$, 1600 mit den Fürstenberg ${ }^{78}$ und schließlich nach langen und mühsamen Verhandlungen durch Bischof Johannes von Waldburg-Wolfegg 1629 mit dem Haus Habsburg. ${ }^{79}$ Sie fügen sich alle in eine lange Reihe inhaltlich ähnlicher Verträge zwischen Territorialherren und Ordinarien, die seit den $1560 \mathrm{er}$ Jahren zustande kamen. ${ }^{80}$ Gerade das Konkordat von 1629 macht deutlich, daß die Kirche nicht nur das Zustandekommen derartiger Vereinbarungen betrieb, sondern ihre Interessen dabei auch zu wahren wußte. Treibende Kraft war der Konstanzer Bischof gewesen, und die Beamten in Innsbruck und Ensisheim hatten gewiß nicht völlig unrecht, wenn sie vor dem Abschluß eines solchen Vertrages immer wieder warnten und statt dessen rieten, sich in den Beziehungen zur Geistlichkeit weiterhin auf das Herkommen zurückzuziehen. ${ }^{81}$ Es gelang bei dieser Gelegenheit, die Kontrolle der Temporalienverwaltung einvernehmlich zu regeln, die weitgehende steuerliche Exemtion der Geistlichkeit festzuschreiben und die Zuständigkeit des forum ecclesiasticum für die Geistlichkeit zu sichern. ${ }^{82}$

Für die Bischöfe aber fast noch wichtiger war die kirchliche Visitationshoheit über Klöster und Säkularklerus. Nach einem ersten Anlauf im Jahr 1550 fanden solche Visitationen, soweit sie von Konstanz aus zu betreiben waren, in den habsburgischen Vorlanden in mehreren Schüben statt. Ein erster erstreckte sich auf die Jahre von 1573 und 1574; 1580/81 visitierte man in Vorarlberg gezielt den Buchbesitz; eine auf das Gesamtbistum zielende Visitation wurde erneut 1586 durchgeführt, die nächste ist für 1595 belegt und schließlich stieß die Synode von 1609 wiederum eine Visitation des Klerus, des Gemeindelebens sowie des Kirchen- und Heiligenvermögens an. ${ }^{83}$

77. Reinhardt, Beziehungen (wie Anm.27), S.70 Anm. 91.

78. Werner Thoma, Die Kirchenpolitik der Grafen vom Fürstenberg im Zeitalter der Glaubenskämpfe (1520-1660). Ein Beitrag zur Geschichte der Kirchenreform und der Konfessionsbildung, Münster 1963, S. 107.

79. Zu Vorgeschichte und Vertrag vgl. Reinhardt, Beziehungen (wie Anm.27), S. $57-70$.

80. Übersichten bei Bücking, Frühabsolutismus (wie Anm.39), S.236f., 69 Anm. 91.

81. Reinhardt, Beziehungen (wie Anm. 27), S. 61 (1602).

82. Der Vertragstext ebd., S. 320-327.

83. Kluckhohn, Urkundliche Beiträge (wie Anm.37), passim; Gmehlin, Visitationsprotokolle (wie Anm.37), passim; Holl, Fürstbischof Jakob Fugger (wie Anm.53), S. 44, $115 \mathrm{ff}$. Zu Visitationen allgemein und zur Aussagekraft von Visitationsprotokollen vgl. Peter Thaddäus Lang, Die Erforschung der frühneuzeitlichen Kirchenvisitationen, in: Rottenburger JbfKG 16 (1997), S. 185-193. 
Als besonders schwierig gestaltet sich hier jeweils das Verhältnis zwischen den Ordinarien und den alten Orden. Der aus vielerlei Gründen als Verfall empfundene Zustand des Klosterlebens in den Abteien und Stiften war seit der Mitte des Jahrhunderts zu deutlich ins Bewußtsein gedrungen, als daß die Bischöfe noch hätten darüber hinwegsehen können. Wo sie sich nicht aus eigenen Stücken dafür interessierten, galt es wenigstens, die landesherrlichen Ansprüche in der Temporalienverwaltung abzuwehren. Im Raum der habsburgischen Vorlande ermöglichte offenbar die immer noch vorhandene Vitalität der Reichsabteien, daß früher als in anderen Regionen des Reiches die Instrumente der wechselseitigen Kontrolle, mit denen die Orden im Spätmittelalter den Zustand ihrer Klöster überwacht hatten, wieder aktiviert wurden. Auf Anstoß der Konstanzer Diözesansynode von 1567 vereinbarten die oberschwäbischen Benediktineräbte, alle drei Jahre zusammenzukommen und sich durch die Äbte von Weingarten und Petershausen visitieren zu lassen. Trotz der Unterstützung durch Nuntius Ninguarda gelang die formelle Gründung der Oberschwäbischen Benediktinerkongregation erst 1602. Die bischöfliche Visitationsgewalt war fortan auf bestimmte Fälle beschränkt. Entsprechend hart war die Auseinandersetzung mit dem Bischof verlaufen. Um ihre Mönche der bischöflichen Visitation zu entziehen, riefen die Klöster einen Großteil von ihnen aus den inkorporierten Pfarreien zurück, woraufhin der Bischof 1597 die zurückgebliebenen seinerseits aus den Pfarreien verwies. ${ }^{84}$

Trotz dieser aus der strukturellen Sonderposition der Orden in der Kirchenorganisation erwachsenden Probleme erwiesen sich die Verdichtung der Visitationstätigkeit und die daraus entstehenden Reformimpulse als wichtiger Beitrag zur Umgestaltung des kirchlichen Raumes und insbesondere zur Bearbeitung derjenigen Probleme, die sich für die im Tridentinum gestärkte bischöfliche Leitungsgewalt aus dem Pfründen- und Eigenkirchenwesen ergaben. An dieser Stelle trat die feudale „Vorgeschichte“ der frühneuzeitlichen Kirchenorganisation mit besonderer Deutlichkeit zu Tage. Die in der Pfründenorganisation begründete Verklammerung von Amt und Beneficium entzog nahezu die Gesamtheit der kirchlichen Amtsträger sowohl hinsichtlich einer eignungsorientierten Auswahl wie dann auch in der aufgabenbezogenen Leitung dem bischöflichen Zugriff und beließ sie statt dessen in den Verwandt-

84. Wolfgang Seibrich, Gegenreformation als Restauration. Die restaurativen Bemühungen der alten Orden im Deutschen Reich von 1580-1648, Münster 1991, S. 20 f., 32. 
schafts-, Klientel- und Patronagebeziehungen, in die sie über den Inhaber der Präsentationsrechte eingebunden waren.

Insbesondere beim adeligen Primarklerus - reguliert oder nicht, spielte nahezu keine Rolle - entsprachen dem in der Regel ein Selbstverständnis und Verhaltensweisen, die den Erfordernissen des kirchlichen Amtes eher zufällig und auch dann noch in höchst unzulänglicher Weise gerecht wurden. Heinrich von Jestetten, der zwei Klöster im Schwarzwald ruinierte und für den sich nach seiner erzwungenen Resignation nicht weniger als 19 Adelige bei Erzherzog Ferdinand verwandten, damit er wegen seines fortgeschrittenen Alters noch eine angemessene "Ergetzlichkeit" erhalte, kann wie der Weingartner Abt Johann Christoph Raittner als Prototypus dieses Klerikers gelten. ${ }^{85}$ Kaum besser - wenn auch mit anderer Symptomatik - präsentierte sich der Sekundarklerus inner- und außerhalb der Klöster. Die Visitationen seit den 1540 er Jahren lieferten überall das gleiche Bild. Man vermag nicht einzuschätzen, ob überhaupt und in welchem Ausmaß von diesen Verhältnissen für die Kirche im 16. Jahrhundert eine Bedrohung ausging. Da allerdings die protestantische Kirchenbildung gangbare Wege aufzeigte, wie man aus Pfründeninhabern Kirchendiener machte, wurden die Zustände in der Römischen Kirche zunehmend dysfunktional.

Die bischöflichen Gegenmaßnahmen lassen sich unter drei Schlagworten rubrizieren: Entfeudalisierung, Disziplinierung und Professionalisierung wenngleich sofort betont werden muß, daß sie zunächst mehr für zaghafte Tendenzen stehen, denn für wirklich einschneidende Veränderungen. Der definitive Schritt von einer Adelskirche zur Bischofskirche sollte in der katholischen Kirche ohnehin erst nach Säkularisation und rechtlichem Zusammenbruch des Ancien Régime gelingen. ${ }^{86}$ Die politischen Optionen und die Einbindung in das Rechtsgefüge des Reiches ließen für Umgestaltungen nur geringen Spielraum. Weder stand es in der Macht der Bischöfe, auf das Pfründenwesen zu verzichten, noch war es möglich, einen Klerus ohne Adelsanteil

85. Gfrörer, Katholische Kirche (wie Anm. 35), S. 489-495; Reinhardt, Restauration (wie Anm. 25), S.10-19; weitere Beispiele aus dem Konstanzer Domkapitel und aus den Stiftern in und um Konstanz bei Karl Schellhaß, Gegenreformation im Bistum Konstanz im Pontifikat Gregors XIII. (1572-1785), Karlsruhe 1925, S. 14-65 und passim.

86. Vgl. zu diesen Vorgängen Rudolf Schlögl, Glaube und Religion in der Säkularisierung. Die katholische Stadt - Köln, Aachen, Münster - 1700-1840, München 1995, S. 127-155. Zum Gesamtprozeß der Neuformung des Klerus siehe jetzt paradigmatisch: Wemer Freitag, Pfarrer, Kirche und ländliche Gemeinschaft. Das Dekanat Vechta 1400-1803, Bielefeld 1998, passim, bes. S.39-225. 
zu formen. Es war allerdings deutlich spürbar, daß man hier daran ging, Grenzen zu ziehen.

Das fing bei Erscheinungsbild und Habitus an. Da die Kleriker sich offenbar bis in den Säkularklerus hinein an ein Auftreten als Standespersonen gewöhnt hatten, verbot man ihnen jetzt - in Konstanz zuerst in den Synodalstatuten von 1567 und dann über die Visitationsinstruktionen - das Tragen von langen Waffen sowie die Beteiligung am Jagdvergnügen. Untersagt wurde auch der Auftritt in spektakulären weltlichen Kleidern, insbesondere den prachtvollen durchbrochenen Hosen. ${ }^{87}$ Das Statut der Konstanzer Domherren von 1616 erinnerte daran, daß die Hunde der hohen Herren im Gottesdienst nichts zu suchen hätten. ${ }^{88}$

Auch bei der Pfründenvergabe selbst geriet der Adel offenbar dort in die Defensive, wo über Wahlgremien und aus der Hierarchie heraus Einfluß genommen werden konnte. Das Konstanzer Domkapitel entschied sich nach Andreas von Österreich und Georg von Hallwyl mit Jakob Fugger (1604-26) und Sixt Werner (1626-27) bewußt und jeweils gegen den Druck der Nuntiatur für Bischöfe bürgerlicher Herkunft. ${ }^{89}$ Im Kloster Weingarten sorgte der ebenfalls bürgerliche Abt Wegelin dafür, daß unter den Novizen der Anteil der Adelsprößlinge deutlich zurückging. ${ }^{90}$ Es scheint symptomatisch, wenn 1609 unter Jakob Fugger in Konstanz die Spannungen im Domkapitel zwischen der Ritterbank und gelehrten Räten in einer offenen Auseinandersetzung um die Besetzung einer Kapitelstelle eskalierten, die sich dann schnell zu einem Grundsatzstreit um die Bedeutung des adeligen Primarklerus für die Kirche auswuchs: Während der schwäbische Adel den Kaiser anrief und den Versorgungsgesichtspunkt betonte, verwiesen die Gelehrten in ihren Polemiken auf die Tatsache, daß wegen notorischer Unbildung keiner von den bepfründeten Adeligen in der Lage sei, eine Funktion in der Verwaltung des Bistums wirklich $\mathrm{zu}$ versehen, und ganz generell die Kirche in jenen Bistïmern sich am besten stehe, in denen Studierte in die Domkapitel aufgenommen wüirden. ${ }^{91}$

87. Synodus Constantiniensis Diocesana ... sub Marco Sitico ... Cardinali et episcopi Constantiniensi celebrata, in: Johann Friedrich Schannart, Joseph Hartzheim, Hermann Scholl (Hgg.), Concilia germania, Bd.7, Köln 1787, S. 539 f. (Pars II, Tit. I, Cap. VI-VIII); Kluckhohn, Urkundliche Beiträge (wie Anm. 37), S. 602, 612, 619.

88. Holl, Fürstbischof Jakob Fugger (wie Anm. 53), S. 199.

89. Zu den Wahlvorgängen vgl. Reinhardt, Beziehungen (wie Anm.27), S. $44 \mathrm{ff.}$., $48 \mathrm{ff}$.

90. Reinhardt, Restauration (wie Anm. 25), S.27-31.

91. Der Streit bei Holl, Fürstbischof Jakob Fugger (wie Anm. 53), S. 200-207; das zitierte Schriftstïck der Gelehrten S. 203 f. 
Das neue Interesse an den Fähigkeiten der Kleriker ergab sich einmal aus dem spürbar besseren Bildungsstand der evangelischen Konkurrenz ${ }^{92}$, dann aber aus der Einsicht, daß das Glaubensleben insgesamt nur zu ändern war, wenn die Kleriker auf den Kaplanei-, Meß- und Pfarrpfründen sich, wie das Tridentinum es vorgesehen hatte, als Gehilfen des Bischofs betätigten und ihren Seelsorgeaufgaben wirklich nachkamen. Dazu war es zunächst nötig, die in allen Visitationen vor Augen geführte Unwissenheit und geistliche Unbildung zu beseitigen: In Freiburg war, wie das Visitationsprotokoll von 1550 festhielt, der sogar promovierte Kapitelsdekan nicht in der Lage zu beten, weswegen ihm der Rat der Stadt dringend nahelegte, künftig keine Messen mehr zu lesen. ${ }^{93}$

Die wenigen Geistlichen mit ausgeprägteren Bildungsinteressen taten sich hingegen immer noch schwer, die Grenzen der Rechtgläubigkeit zu erkennen. Für sie übte das intellektuelle Klima der neuen Lehre gerade dann eine große Anziehungskraft aus, wenn sie sich nicht zu einem formalen Wechsel entschlossen. Spektakulär war der Fall des Konstanzer Pfarrers bei St. Stephan, Dr. Sandholzer, dem 1562 der Prozeß gemacht werden sollte, weil er für sich in Anspruch nahm, den Frieden zwischen den Glaubensparteien zu fördern, indem er auf den Usus in der alten Kirche hinwies, das Abendmahl in beiderlei Gestalt zu feiern. Fastengebot und Zölibat relativierte er, indem er ihre Geschichtlichkeit aufwies. ${ }^{94}$ Andere Geistliche hielten sich öffentlich mehr zurück, ließen aber in ihrem Buchbesitz erkennen, daß sie vom theologischen Diskurs der Evangelischen profitieren wollten wie auch deren Bibelübersetzungen für nützlich hielten. ${ }^{95}$ Erst nach der Jahrhundertwende gelang es schließlich, die theologische Grenze zu befestigen und die „Katholizität“ des Klerus sicherzustellen. ${ }^{96}$

92. Mit regionalem Bezug Wilfried Enderle, Konfessionsbildung und Ratsregiment in der katholischen Reichsstadt Überlingen (1500-1618) im Kontext oberschwäbischer Reichsstädte, Stuttgart 1990, S.270; vgl. hierzu jetzt allgemein: Luise Schom-Schiitte, Evangelische Geistlichkeit in der Frühneuzeit. Deren Anteil an der Entfaltung frühmoderner Staatlichkeit und Gesellschaft. Dargestellt am Beispiel des Fürstentums Braunschweig-Wolfenbüttel, der Landgrafschaft Hessen-Kassel und der Stadt Braunschweig, Heidelberg 1996, S. 159-226.

93. Kluckhohn, Urkundliche Beiträge (wie Anm. 37), S. 617.

94. Wolfgang Zimmermann, Rekatholisierung, Konfessionalisierung und Ratsregiment. Der Prozeß des politischen und religiösen Wandels in der österreichischen Stadt Konstanz 1548-1637, Sigmaringen 1994, S. 157 ff.

95. Thoma, Fürstenberg (wie Anm.78), S. 126 Anm. 332: Bibliothek des „Ausnahmepfarrers" Reinhart Robert in Wolfach, Konventuale des Klosters St. Peter im Schwarzwald.

96. Vgl. mit Beispielen aus rheinisch-westfälischen Bistümern Karl Hengst, Kirche 
Dazu trug eine Vielzahl von Einzelschritten und unterschiedlich verorteten Entwicklungen bei. Da es nur noch in engen Grenzen möglich war, den bereits bepfründeten Klerus zu ändern, mußte der Akzent auf Bildung und Auswahl der künftigen Seelsorgergenerationen gelegt werden. Schon seit der Mitte des Jahrhunderts unterstrichen die Bischöfe ihr Mitwirkungsrecht an der Pfründenvergabe, indem sie auf dem förmlichen Akt der bischöflichen Investitur bestanden, der von der Pfründenübertragung durch den Patronatsherrn häufig beiseite gedrängt worden war. ${ }^{97}$ Die Synode von 1567 setzte ein ausführliches Examen als Bedingung der Ordination und verlangte von den Kandidaten entsprechend den tridentinischen Canones die Befähigung zur wissenschaftlichen Gelehrsamkeit. ${ }^{98}$ Unter Jakob Fugger kam es bereits dazu, daß der Generalvikar unwürdigen und unfähigen Geistlichen die Ausübung ihres Seelsorgeamtes verbot. ${ }^{99}$ Ein Studium der Rhetorik und der Dialektik samt einem zweijährigen Kurs in Kasuistik an einer katholischen Universität oder wenigstens einem Gymnasium schon für die Subdiakonatsweihe stipulierte dann die Synode von 1609. ${ }^{100}$ Zwischenzeitlich hatte der Anteil der Geistlichen mit Universitätsstudium sich allerdings bereits erheblich verstärkt. ${ }^{101}$

Wo dieses Studium unter jesuitischer Führung absolviert wurde, verband sich damit im übrigen auch gegenüber Externen ein strenges, charakter- und habitusformendes Erziehungsprogramm, das entsprechend der in den Jesuitenkonventen realisierten Lebens- und Erziehungsordnung auf Selbstdisziplin, Abgrenzung zur Welt und die unbedingte Bereitschaft gerichtet war,

und Konfessionsbewußtsein im Klerus des 16. Jahrhunderts. Ein Beitrag zum Problem der Konfessionsbildung, in: Walter Brandmiiller, Herbert Immenkötter, Erwin Iserloh (Hgg.), Ecclesia militans. Studien zur Konzilien- und Reformationsgeschichte. Remigius Bäumer zum 70. Geburtstag gewidmet, Bd.2, Paderborn 1988, S. 587-605, hier S.604f. Ein Großteil des gebildeten, reformwilligen Klerus gehört nach dem Befund der dortigen Visitationsprotokolle zu den „Erasmianern“.

97. Dies ist ein wesentliches Anliegen der Visitationen von 1550 bis Mitte der 1570er Jahre. Vgl. G. Bossert, Die Visitationsprotokolle der Diözese Konstanz von 1574 bis 1581, in: Blätter für Württembergische Kirchengeschichte 6 (1891), S.43-46 (Landkapitel Isny, 1576); Reinhardt, Beziehungen (wie Anm. 25), S. 232 ff.

98. Synodus 1567 (wie Anm. 87), S. 494, 496 (Pars I, Tit. XIV, Cap. I, XII).

99. Reinhardt, Beziehungen (wie Anm. 25), S. 237.

100. Synodus 1609 (wie Anm. 64), S. 871 (Pars I. Tit. XIV, Cap. XI).

101. Enderle, Überlingen (wie Anm.92), S.256ff. Man muß dabei allerdings in Rechnung stellen, daß die Verhältnisse in den ländlichen Pfarreien längst nicht so günstig waren, da die besser dotierten Stellen in der Stadt vergeben wurden. 
sich der Leitungsgewalt einer Hierarchie auszuliefern. ${ }^{102}$ Dies verstieß so sehr gegen Ehr- und Sozialnormen der säkularen Lebenswelt, daß es an der Jesuitenuniversität Dillingen sogar mit bürgerlichen Stipendiaten aus den katholischen Städten zu schweren Konflikten um die Disziplin kam. ${ }^{103}$

Seit den 1560 er Jahren wurde für den verpfründeten Klerus in den habsburgischen Vorlanden in vielfältiger Weise spürbar, daß die kirchliche Hierarchie auf ihren Leitungs- und Disziplinarbefugnissen in einer ungekannten Weise bestand. Der fast absolutistische Führungsstil Wegelins in der Abtei Weingarten ${ }^{104}$ brachte dies ebenso zum Ausdruck wie die wiederkehrenden bischöflichen Visitationen, denen sich die Pfründner außerhalb der Klöster ausgesetzt sahen. Da die direkte Reichweite des bischöflichen Armes begrenzt war, setzten die Ordinarien auf die beaufsichtigende und regulierende Kraft der Landdekane. Ihre Befugnisse und Zuständigkeiten umschrieb bereits die Synode von 1567 detailliert. Gewählt vom Klerus des Dekanatsbezirkes repräsentierten sie die bischöfliche Disziplinargewalt vor Ort und sollten durch regelmäßige Visitationen dafür sorgen, daß Kirchengebäude und Kirchenfabriken und Heiligenvermögen nicht verkamen. ${ }^{105}$ Die Synode von 1609 verfeinerte den Aufgabenkatalog und rief die Pflicht zu regelmäßigen Kapitelsversammlungen in Erinnerung, auf denen die Priester ihre Verfehlungen wechselseitig kontrollieren sollten. ${ }^{106}$ Bei den Visitationen übernahmen die Ruraldekane eine wichtige Rolle. ${ }^{107}$ Dabei kam freilich an den Tag, daß viele von ihnen über die Geistlichkeit ihres Dekanatsbezirkes kaum Bescheid wußten und bei offenkundigen Verfehlungen große Nachsicht zeigten. ${ }^{108}$

Insgesamt aber trugen auch die Landdekane dazu bei, daß der Klerus in den Diözesen sich mit einem immer dichteren Netz an Verhaltensvorschriften konfrontiert sah, das darauf abzielte, für die Geistlichen eine von der Kleidung bis hin zu Auswahl sozialer Kontakte sichtbare Sonderform der Lebensführung zu definieren und sie damit letztlich neben die ständische Sozialordnung zu stellen. Der vorbildliche Pfarrer sollte ein würdiger Herr sein, dessen Weihe besonders darin zum Ausdruck kam, daß er Distanz zu seiner Gemeinde hielt, nicht mit seinen Bauern auf der Kegelbahn trank, bevor er an den Al-

102. Hermann Stoeckius, Forschungen zur Lebensordnung der Gesellschaft Jesu im 16. Jahrhundert, 2 Teile, München 1910/11, hier: Teil I, S. 34 ff.; Teil II, S. 162 ff.

103. Enderle, Überlingen (wie Anm. 92), S.332f.

104. Reinhardt, Restauration (wie Anm. 25), S. 60 f.

105. Synodus 1567 (wie Anm. 87), S. 548 ff. (Pars II, Tit. III).

106. Synodus 1609 (wie Anm. 64), S. 895 ff. (Pars II, Tit. III).

107. Kluckhohn, Urkundliche Beiträge (wie Anm. 37), S.621ff.

108. Gmehlin, Visitationsprotokolle (wie Anm. 37), S.175, $186 \mathrm{f}$. 
$\operatorname{tar}$ schritt $^{109}$, und der schon gar nicht in den städtischen Hurenhäusern zu finden war. ${ }^{110}$

Ein Großteil der bis jetzt angesprochenen Entwicklungen kulminierte in der Zölibatsfrage. In nahezu allen Dekanatsbezirken hatten die Visitatoren seit den 1570 er Jahren bei wenigstens zwei Dritteln der Kleriker Konkubinen ermittelt. ${ }^{111}$ Bezeichnend war, daß die Geistlichen nicht etwa nur gelegentlich verschämt Kinder mit ihren Lebensgefährtinnen gezeugt hatten, sondern zu einem Großteil in bewußt eheänlichen Verhältnissen lebten, denen sie in vielen Fällen etwa durch testamentarische Verfügungen zugunsten der Frau und der gemeinsamen Kinder einen rechtsförmigen Status zu geben trachteten. ${ }^{112}$ Gerade dies führt noch einmal vor Augen, wie schwierig es für die alte Kirche war, sich aus der Gravitation des bestehenden Sozialgefüges zu befreien und sich eine neue Struktur zu geben. Man trifft daher an dieser Stelle nicht auf „Verfall“ oder „Wildwuchs“, sondern auf die Folgen eines die römische Kirche der Zeit in den Fundamenten prägenden Strukturzusammenhanges.

Im Konkubinat versammelte sich die vollständige „Gewöhnlichkeit" und Erdenschwere der Klerikerexistenz, die wegen des Pfründenwesens zunächst als Versorgungsinstitut gegenübertrat, das keinerlei Distinktion in der Lebensführung nahelegte. Es schien daher keinerlei Notwendigkeit zu geben, sich zölibatäre Enthaltsamkeit aufzuerlegen. Für die Pfründeninhaber der Landpfarreien lag zudem auf der Hand, daß sie den bäuerlichen Betrieb ihres Pfarrwidums schon allein wegen der Viehhaltung ohne die Hilfe von jungen, kräftigen Mägden nicht zu führen vermochten. ${ }^{113}$ Die Landkapitel wiesen auf diese rauhen Bedingungen der ländlichen Existenz bereits bei der Synode von 1567 und dann immer wieder hin unnahmen dies auch als Begrün-

109. Kluckhohn, Urkundliche Beiträge (wie Anm.37), S.618; Gmehlin, Visitationsprotokolle (wie Anm. 37), S. 203; Thoma, Fürstenberg (wie Anm. 78), S. 121: Der Pfarrer von Hausach trägt ein Wollhemd und Bauernkleidung, hört die Beichte hinter dem Pflug oder im Pfarrhaus und erteilt auch immer gleich die Absolution. Trotz Supplikation der Gemeinde wird er entlassen.

110. Kluckhohn, Urkundliche Beiträge (wie Anm.37), S.616.

111. Thoma, Fürstenberg (wie Anm.78), S.121f.; Gmehlin, Visitationsprotokolle (wie Anm. 37), S. 178 ff. Siehe neuerdings zu diesem Thema: Eva Labouvie, Geistliche Konkubinate auf dem Land. Zum Wandel von Ökonomie, Spiritualität und religiöser Vermittlung, in: GuG 26 (2000), S. 105-127, bes. S. 107-117.

112. Beispiele bei Schellhaß, Gegenreformation (wie Anm.85), S.34: Der Abt von St. Georgen läßt sich vom Konvent für seine Töchter eine Ausfertigung zusichern. Kluckhohn, Urkundliche Beiträge (wie Anm. 37), S. 616, 622.

113. Thoma, Fürstenberg (wie Anm. 78 ), S. 122 Anm. 310, S. 125. 
dung für die Unmöglichkeit, die Landgeistlichen von ihren Frauen zu trennen. ${ }^{114}$

Obwohl die Kirche seit dem Spätmittealter mit der Spannung des übertretenen Zölibats umzugehen gelernt hatte, schien sie jetzt für die reformbereiten Vertreter der kirchlichen Obrigkeit nicht mehr hinnehmbar. Die durch die Visitationen augenfällig gewordene Häufung der Übertretung mag dazu beigetragen haben, aber mindestens ebenso gewichtig wurde das Problem der Abgrenzung, nachdem sich bei den Evangelischen die Pfarrfamilie als neue Sozialform des geistlichen Lebens herausbildete. ${ }^{115}$ In einer Marginalie zu der im Hohenzollernschen gebrauchten Visitationsinstruktion von 1591 war zu diesem Punkt zu lesen: „Gott der herre verleih sin Gnad, dz ob diesn hailsamen statuen fleissig und ernstlich gehalten wird, so werden wir unsern widersachern nit also im mauhl herumb fahren. ${ }^{\text {"116 }}$

Trotz der 1586 eingeforderten Unterstïtzung der weltlichen Gewalt zur Abschaffung des Zölibats waren die Erfolge auf allen diesen Feldern in der bepfründeten Generation der Kleriker mehr als mäßig. Erst die Visitationen ab dem ersten Jahrzehnt des 17. Jahrhunderts lassen dann einen Klerus erkennen, der das geforderte Mindestmaß an universitärer Bildung aufwies, der seinen Buchbeständen nach zu schließen die Konfessionsgrenzen auch in seinen intellektuellen Horizont eingeschrieben hatte ${ }^{117}$ und der in seiner Lebensführung sich nicht mehr so sehr als Pfründner präsentierte, sondern als Verwalter der kirchlichen Gnadenmittel und als Glied einer Kirche, die sich als verschieden von der weltlichen Sozialordnung begriff, als Gegenüber der staatlichen Macht und erst recht auch der Hierarchie einer auf den Adel zentrierten Ständeordnung.

Die Reformation hatte sich als theologische Offensive und als Alternative der Glaubenspraxis entfaltet. Theologen und Hierarchie der römischen Kirche

114. Synodus 1567 (wie Anm. 87), S. 435 f.; Kluckhohn, Urkundliche Beiträge (wie Anm. 37), S.613, 616.

115. Vgl. Schorn-Schïtte, Evangelische Geistlichkeit (wie Anm. 92), S. $287 \mathrm{ff.}$

116. Manfred Huber, Die Durchführung der tridentinischen Form in Hohenzollern (1567-1648), Diss. phil., Tübingen 1963, S.71.

117. Thoma, Fürstenberg (wie Anm.78), S.179-184; Huber, Hohenzollern (wie Anm. 116), S. 75 f. Allgemein zur Wiederannäherung des katholischen und des evangelischen Klerus im Bildungsstand und zur Vergleichbarkeit der Rekrutierungsmuster vgl. Luise Schorn-Schiitte, The Christian Clergy in the Early Modern Holy Roman Empire: A Comparative Social Study, in: Sixteenth Century Journal 29 (1998), S.717731. 
neigten in ihren Reformbestrebungen zunächst dazu, diese Herausforderung zu ignorieren und eine offensive Auseinandersetzung zu verweigern, da man sich im Bewußtsein der rechten Lehre wußte. ${ }^{118}$ Es spricht daher für die Eigendynamik der Konfessionalisierung (wie für ihren konfessionsübergreifenden Charakter), wenn die tridentinische Kirche auf diesem Feld in der zweiten Hälfte des 16. Jahrhunderts einen erkennbaren Lernprozeß durchlief. $\mathrm{Da}$ man sich von der Welt der Evangelischen aus vielerlei Gründen nicht isolieren konnte, mußte den Gläubigen jetzt das dogmatische Proprium des „alten Glaubens" deutlicher als bisher verständlich gemacht und in den Menschen eine sichtbar distinktiv wirkende Glaubenspraxis umgesetzt werden. Weil die Menschen, wie das Kitzigtal und andere Gebiete mit gemischtem Bekenntnisstand erwiesen, in Glaubensdingen zu Irenik und synkretistischen Mischformen neigten ${ }^{119}$, blieb dies eine schwierige Aufgabe, deren Bewältigung schließlich auch auf die Form des Glaubens selbst zurückwirkte.

Um die Richtung der Veränderungen zu erfassen, kann man sich an die Programmatik der Synoden halten und an die Visitationspraxis, da hier die Umgestaltungsabsichten am konzentriertesten zusammenflossen.

Der auffälligste Zug ist dabei das Bemühen, den kirchlichen Raum in seiner Sakralität zu heben und diese sichtbar und erfahrbar zu machen. Dies schloß an die Umprägung des priesterlichen Habitus an, erfaßte aber sehr viel weitere Bereiche. Betont wurde die Feierlichkeit des Gottesdienstes, seine würdige Gestaltung, und um dies sicherzustellen, war es notwendig, alle Weltlichkeit aus seiner zeitlichen und räumlichen Nähe fernzuhalten. Daher sollten die Wirtshäuser während des Gottesdienstes geschlossen bleiben, die Arbeit an Sonn- und Feiertagen ruhen ${ }^{120}$, der Kirchhof sauber gehalten und gegen das

118. Vgl. auch Klaus Ganzer, Das Konzil von Trient und die theologische Dimension der katholischen Konfessionalisierung, in: Reinhard, Schilling (Hgg.), Katholische Konfessionalisierung (wie Anm. 5), S. 50-69, bes. S. 51 ff., 67 f.

119. Thoma, Fürstenberg (wie Anm.78), S.66, 70-77, 84-92; vgl. auch Karl Siegfried Bader, Das badisch-fürstenbergische Kondominat im Prechtal, Freiburg 1934, S.119ff. Neuere Untersuchungen von Werner Troßbach zum mehrfachen Konfessionswechsel unter Laien legen allerdings nahe, dieses Verhalten nicht als Desinteresse zu interpretieren, sondern als Versuch, den Gewissensnöten und Heilsunsicherheiten, die aus Konfessionswechseln erwuchsen, zu entgehen: Werner Troßbach, Volkskultur und Gewissensnot. Zum Bilderstreit in der „Zweiten Reformation" in: ZhF 23 (1996), S. 473-500, bes. S. 493-498.

120. Vgl. die Instruktion für die Visitatoren: Gmehlin, Visitationsprotokolle (wie Anm.37), S. $145 \mathrm{ff}$. An dieser Stelle ist gut sichtbar, daß die (Webersche) Frage nach Motiven in die Irre führt, weil sozialer Sinn natürlich immer ein mehrfacher ist: Diese Maßnahmen unterstreichen die Grenzziehung zur Welt, und sie erhöhen gleichzeitig 
Vieh abgesperrt werden. Überhaupt achtete man auf Reinlichkeit des Kirchengeräts, um die Heiligkeit der Gegenstände zu unterstreichen. Der ordentliche Zustand der Meßgewänder wurde angemahnt; das Taufbecken sollte vor Verschmutzungen geschützt werden. Für die Aufbewahrung heiliger Substanzen, wie geweihtes Öl, Crisam und vor allem der Hostien, formulierte man genaue Vorschriften.

Besondere Aufmerksamkeit zog dabei nach und nach die Hostie auf sich. Sie rückte ein in die Stellung des „Allerheiligsten“, weil sich im Wunder der Transsubstantiation die universale Macht und das heilige Wirken des Priesters und davon abgeleitet die Benediktionsgewalt der Kirche in besonderer symbolischer Klarheit darstellen ließ. Deswegen war es nicht länger hinnehmbar, wenn die Bauern beim Umtragen des Allerheiligsten mit offenen Mäulern dastanden, die Hüte auf dem Kopf behielten und nicht einer auf die Idee kam, das Knie zu beugen. ${ }^{121}$ Die Konstanzer Synode von 1567 machte es daher dem Klerus zur wichtigen Aufgabe, den Gläubigen das Geheimnis des Meßopfers und der Wandlung auseinanderzulegen und nahezubringen. ${ }^{122}$

An dieser Stelle begann freilich auch schwieriges Terrain für die Kirche, denn der Bedarf an beschirmender Kraft des Himmels war groß unter den Gläubigen. Sie erwarteten nicht nur Hilfe auf dem Weg zum jenseitigen Heil, wie die Kirche sie als Verwalterin der Gnadenmittel geben konnte, sondern beanspruchten sie auch als Mittlerin, der es möglich war, die Allmacht Gottes und die Kraft der Heiligen zur Linderung der irdischen Not herabzuflehen. Religion und Lebenswelt blieben verwoben. ${ }^{123}$ Das 16 . Jahrhundert setzte hier die spätmittelalterliche Frömmigkeitsgeschichte fort und ließ vorerst auch keinen Unterschied zwischen Volks- und Elitenreligiosität erkennen. ${ }^{124}$ Nicht nur, weil die Protestanten über Benediktionen und Heiligenverehrung spotte-

die konfessionelle Grenze, weil diejenigen, die an Heiligenfesten arbeiten, die „anderen" sind.

121. So noch in einer Visitation von 1623 aus dem Kapitel Wurmlingen im Fürstenbergischen berichtet; vgl. Thoma, Fürstenberg (wie Anm. 78), S. $190 \mathrm{f}$.

122. Synodus 1567 (wie Anm. 87), S. 474 (Pars I, Tit. VI, Cap. VIII).

123. Vgl. auch Andreas Holzem, Katholische Konfession und Kirchenzucht. Handlungsformen und Deliktfelder archidiakonaler Gerichtsbarkeit im 17. und 18. Jahrhundert, in: Westfälische Forschungen 45 (1995), S. 295-332, bes. S. 299 f.

124. Vgl. Klaus Schreiner, Laienfrömmigkeit - Frömmigkeit von Eliten oder Frömmigkeit des Volkes? Zur sozialen Verfaßtheit laikaler Frömmigkeitspraxis im späten Mittelalter, in: Klaus Schreiner ( $\mathrm{Hg}$.), Laienfrömmigkeit im späten Mittelalter. Formen, Funktionen, politisch-soziale Zusammenhänge, München 1992, S. 1-78, hier: S. 62 f.; Werner Freitag, Volks- und Elitenfrömmigkeit in der Frühen Neuzeit. Marienwallfahrten im Fürstbistum Münster, Paderborn 1991, S. $221 \mathrm{ff}$. 
ten $^{125}$, entstanden hier aber Spannungen, sondern weil an dieser Stelle eine Vermischung des Heiligen und des Profanen stattfand, die sowohl der Sonderstellung des Priesters wie überhaupt der Autonomie des Sakralen zuwiderlief.

Man kann die wachsende Sensibilität der Kirche für diesen Zusammenhang beobachten, wenn man die Synodalstatuten von 1567 und 1609 gegeneinanderhält. Erst 1609 befaßt sich ein erheblicher Anteil der Einzelkapitel mit Mißverständnissen und Mißbräuchen, die in der Heiligenverehrung, im Gebrauch der Benediktionen und vor allem im Umgang mit dem Allerheiligsten aufzuspüren waren. Ein durchgehender Zug aller dieser Anordnungen war, den Gebrauch des Allerheiligsten einzig dem Priester vorzubehalten, auf diese Weise seine Verfügbarkeit für die Gläubigen zu limitieren und es ausschließlich auf seine Funktion als Heilmittel der Seele zu beschränken. Hostien sollten sorgfältig aufbewahrt werden, um sie vor Mißbrauch und Einsatz im Volkszauber zu schützen; sie durften nicht mehr einfach von Laien aus der Kirche heraus zu Kranken getragen werden; die Aussetzung des Allerheiligsten war auf bestimmte Tage zu beschränken, und es sollte dann in würdiger, ehrfurchtgebietender Weise präsentiert werden. Seit einiger Zeit waren dafür prachtvolle Gefäße, Monstranzen genannt, in Gebrauch. ${ }^{126}$ Verboten wurde die Verwendung des Allerheiligsten zum Schutz vor Ungewittern und anderen Naturgewalten. Den in vielen Gemeinden lebendigen Brauch, das Allerheiligste um die Felder zu tragen, könne man nicht abschaffen, ohne Ärgernis zu erregen, hieß es 1609; aber die Prozession solle sich dann wenigstens in größter Ehrfurcht vollziehen, damit Gott dadurch nicht beleidigt werde und anstatt Wachstum Unfruchtbarkeit die Folge sei. In die gleiche Richtung wiesen Bestimmungen, wonach man die Heiligenverehrung weiterhin fördern, aber unbedingt verhindern solle, daß Reliquien in die Hände von Laien gelangten. Die Heiligenbilder unterlagen bischöflicher Zensur, damit die „lächerlichen“ und „anstößigen “ ausgeschieden würden. Wunder mußten ebenfalls sofort an den Bischof gemeldet werden, damit man sie prüfen könne und kein Aberglaube entstehe. ${ }^{127}$

Trotz aller Bereitschaft der tridentinischen Kirche, die gelebte Volksfrömmigkeit lebendig zu halten und aufzunehmen, wirkte an dieser Stelle mit Macht die Eigengesetzlichkeit des laufenden Integrationsprozesses. Die Sta-

125. Beispiele aus dem 17. Jahrhundert bei Volkland, Konfessionelle Grenzen (wie Anm. 63), S. $376 \mathrm{ff}$.

126. Synodus 1609 (wie Anm. 64), S. 860 (Pars I, Tit. VIII, Cap. XXVI).

127. Synodus 1609 (wie Anm. 64), S. 884 (Pars I, Tit. XXI, Cap. III). 
bilisierung der Kirche als Sozialraum eigener Logik und eigener Wertehierarchien vollzog sich im Sozialen als Trennung des Heiligen vom Profanen und in der intellektuellen Konstitution der Welt, indem die Transzendenz nach und nach auf das Geistige beschränkt und der Bereich der Natur seiner ihm eingeschriebenen Gesetzlichkeit überlassen wurde. Das Außer- und Übernatürliche ${ }^{128}$ konzentrierte sich schließlich in der geheiligten Sphäre einer Kirche, die - jedenfalls in ihrer Theologie, weniger in der seelsorgerlichen Praxis - immer zurückhaltender wurde, wenn die Gläubigen um die Beeinflussung von Naturzusammenhängen beteten. Auch hier arbeitete man an der Entzauberung der Welt. Nichts anderes war gemeint, wenn den Pfarrgeistlichen verboten wurde, ärztliche Künste auszüben, man sie aber gleichzeitig anhielt, den Gebrauch des Sakraments der Letzten Ölung zu fördern. ${ }^{129}$ Sakralisierung verband sich daher an jeder Stelle unauflöslich mit Säkularisierung auf der anderen Seite. ${ }^{130}$

Da ein scharfer Bruch mit den volksreligiösen Traditionen nicht gewollt war und die laufende innere Missionierung auch nur behindert hätte, vollzog die tridentinische Kirche hier weiterhin eine Gratwanderung. Allerdings läßt sich auch auf Seiten der Gläubigen beobachten, daß die angestrebte Erneuerung und Intensivierung des religiösen Lebens nicht nur alte Formen der Frömmigkeit wiederbelebte, sondern zaghaft einen neuen Frömmigkeitsstil schuf. Das Stiftungswesen erlebte seit den 1580er Jahren in den Städten und Landgemeinden des Vorlandes wieder einen Aufschwung. Bruderschaften und Marianische Kongregationen entstanden - vor allem auf Initiative der Jesuiten und der Kapuziner - vermehrt seit dem ersten und zweiten Jahrzehnt des neuen Jahrhunderts. Auch an dieser Stelle war die Verselbständigung des Religiösen spürbar: die Bruderschaften des 17. Jahrhunderts verzichteten auf die Komponente sozialer Unterstïtzung, wie sie das Bruderschaftswesen des Spätmittelalters ausgezeichnet hatte, und wurden als reine Gebetsbruderschaften geführt. In den Stiftungen trat ebenfalls der Gedanke sozialer Unter-

128. Zur Diskussion um dieses Begriffspaar im 16. Jahrhundert vgl. Lorrain Daston, Wunder und Beweis im frühneuzeitlichen Europa, in: Garry Smith, Matthias Kroß (Hgg.), Die ungewisse Evidenz. Für eine Kulturgeschichte des Beweises, Berlin 1998, S. 13-68, hier bes. S. 29-38.

129. Synodus 1609 (wie Anm.64), S.867, 893 (Pars I, Tit. XII, Cap. II; Pars II, Tit. I, Cap. XXIX).

130. Zum Begriff vgl. Hartmut Lehmann (Hg.), Säkularisierung, Dechristianisierung, Rechristianisierung im neuzeitlichen Europa, Göttingen 1997; Für einen systemtheoretisch fundierten Begriff von Säkularisierung plädiert Schlögl, Glaube und Religion (wie Anm. 86), S. $23 \mathrm{ff}$. 
stützung und öffentlicher Repräsentation zurück gegenüber der Sicherung des Seelenheils. ${ }^{131}$

Aus der Aufwertung der Messe und der Kommunion ergab sich mit einer gewissen Zwangsläufigkeit die steigende Bedeutung der Beichte. Visitationsinstruktionen und Synodalstatuten suchten ihr eine strengere Form zu geben, um ihren sakramentalen Charakter zu unterstreichen. Sie sollte in der Kirche, nicht in der Sakristei oder im Pfarrhaus, und zwar einzeln, abgenommen werden; die Beichtenden waren gehalten, ihre Sünden, eine nach der anderen, genau und nicht summarisch zu benennen. ${ }^{132}$ Hier werden erste Ansätze einer Moralisierung und Verinnerlichung des Religiösen faßbar, die freilich für die Masse der Gläubigen für sich genommen nicht sehr tief gehen konnten und die man daher in diesem Stadium noch kaum als überzeugendes Argument für den Prozeß der Sozialdisziplinierung anführen kann. Schon eher läßt sich in den zum Teil neu eingeführten Kommunions- und Beichtregistern beobachten, wie auch die Kirche ein bürokratisches Verhältnis zur Herde der Gläubigen suchte. Bürokratisierung der pastoralen Praxis und Institutionalisierung der Introspektion fügen sich in jenes Syndrom der methodischen Rationalisierung der Lebensführung, die Max Weber fast ausschließlich im asketischen Protestantismus entdecken konnte. Die Parallele ging freilich offenkundig noch viel weiter. Sie erstreckte sich auch auf die sehr eingeschränkte Wirksamkeit des religiösen Normenapparates ${ }^{133}$, so daß nach unseren Beobachtungen die von Max Weber vermutete besondere Nähe von Protestantismus und Kapitalismus gleich von mehreren Seiten her in Frage gestellt ist.

Die Visitationen im vorländischen Raum lassen in allen diesen Bereichen nur sehr eingeschränkt Drängen und Eigeninitiative der Gläubigen erkennen. Für sie kam es darauf an, die heilsnotwendige Versorgung mit Sakramentalien sichergestellt zu wissen. Es läßt sich nicht ausschließen, daß die Bedrohungen der ökonomischen und sozialen Krise seit den 1580er Jahren die Aufgeschlos-

131. Enderle, Konfessionsbildung (wie Anm. 92), S. $306 \mathrm{ff} ., 345 \mathrm{ff}$.

132. Synodus 1609 (wie Anm. 64), S. 862-864 (Pars I, Tit. X-XI).

133. Heinz Schilling betont die verhaltens- und motivsteuernde Kraft der katholischen Beichtpraxis: Schilling, Konfessionalisierung (wie Anm. 5), S. 38-40. Der theologische Diskurs samt der Glaubenspraxis des 18. Jahrhunderts scheinen dies allerdings nicht zu bestätigen. Vgl. hierzu Rudolf Schlögl, Öffentliche Gottesverehrung und privater Glaube in der frühen Neuzeit. Beobachtungen zur Bedeutung von Kirchenzucht und Frömmigkeit für die Abgrenzung privater Sozialräume, in: Gert Melville, Peter von Moos (Hgg.), Das Öffentliche und das Private in der Vormoderne, Köln usw. 1998, S. 165-209, hier S. 204. 
senheit für die tröstende Kraft der Kirche erkennbar hoben, aber die belehrenden Unterweisungen in der regulären Seelsorge griffen nur sehr zögernd. Über die Wirkungen der Predigt, die nach dem Willen der Synoden verstärkt der Erklärung des Evangeliums und der übrigen Glaubensgeheimnisse gewidmet werden sollte, geben die Visitationsberichte nur mangelhaft Auskunft. Nachvollziehbar ist in ihnen aber, daß die von den Ordinarien und der weltlichen Obrigkeit verfügte Regelmäßigkeit der Kinderkatechese in vielen Fällen nicht umgesetzt wurde und umgekehrt die Familien ihre Kinder nicht zum regelmäßigen Besuch anhielten. ${ }^{134}$ Die innere Missionierung ruhte daher hauptsächlich auf den Schultern der neuen Orden, wobei die Jesuiten bei der geistlichen wie der weltlichen Obrigkeit lange gegen größere Vorbehalte zu kämpfen hatten als die Kapuziner. Hierarchie und organisatorische Hermetik des Jesuitenordens ließen ihn zu einem Fremdkörper in den laufenden regionalen kirchlichen und staatlichen Integrationsprozessen werden. Es ist bezeichnend, daß man sich auf den Orden erst einlassen wollte, nachdem der Entwicklungsprozeß eine gewisse Stabilität erreicht hatte. Zwar wirkten die Jesuiten bereits seit 1551 mittelbar in den Vorderösterreichischen Landen durch die Universität Dillingen und die Inspiration, die von dort auf die Abteien der alten Orden, wie etwa Weingarten, ausgriff. Zum Aufbau eines Netzes jesuitischer Bildungseinrichtungen und eigener Niederlassungen kam es aber erst seit 1604. Am Beginn stand das Gymnasium in Konstanz, es folgte im selben Jahr Hagenau im Elsaß. Eine Niederlassung in Schlettstadt wurde 1615 eingerichtet, $1620 \mathrm{kam}$ es nach langen Anläufen zur Übernahme der Universität Freiburg durch die Jesuiten und 1649 folgte noch eine Niederlassung in Rottenburg. ${ }^{135}$ Dagegen bauten die Kapuziner ihre Niederlassungen in diesem Raum bereits seit den 1580 er Jahren aus. Bis 1600 lagen die Gründungen noch allesamt in den katholischen Kantonen der Schweiz, seit 1603 lief die Initiative einer Klostergründung in Konstanz, 1623 folgte Biberach, 1623 Rottenburg und Radolfzell, 1625 noch Rottweil. Insgesamt 21 Klöster zählte der Orden während der Amtsführung Jakob Fuggers im Bistum Konstanz. ${ }^{136}$

Die theologische Formierung der tridentinischen Kirche und die Umgestaltung des Glaubensvollzugs zeichnete sich trotz der offenkundigen Abgren-

134. Vgl. Thoma, Fürstenberg (wie Anm.78), S.129; Huber, Hohenzollern (wie Anm. 116), S.75.

135. Zur Geschichte der Jesuiten im Raum vgl. Theodor Kurrus, Die Jesuiten in Freiburg und in den Vorlanden, in: Maier, Press (Hgg.), Vorderösterreich (wie Anm. 29), S. $271 \mathrm{f}$.

136. Holl, Fürstbischof Jakob Fugger (wie Anm. 53), S. 86 ff., $106 \mathrm{ff}$. 
zung von der "protestantischen Häresie “ durch das Bestreben aus, nicht die Auseinandersetzung zu suchen, sondern die Gläubigen abzuschließen. Die Synoden mahnten den Klerus, in den Predigten vorsichtig zu sein und die Argumente und Ansichten der Evangelischen nicht zu nennen und zu diskutieren. ${ }^{137}$ Aus den seit den 1580er Jahren ins Werk gesetzten Buchvisitationen, der Kontrolle des Buchvertriebes und schließlich der Buchzensur spricht der gleiche Geist. Erst die barocke Kontroverstheologie und die Kontroverspredigt beendeten diese Defensive. ${ }^{138}$

Trotzdem: die tridentinische Reform der römischen Kirche verlief als ein Prozeß der Grenzziehung und Stabilisierung, als ein Prozeß, in dessen Fortgang sie sich dogmatisch, institutionell und im Glaubensvollzug zur katholischen Konfessionskirche integrierte. Zwar wirkten die Grundstrukturen der feudalen Ordnung in ihrer Organisation fort, aber es gab an vielen Stellen wirksame Ansätze, die daraus erwachsenden Beschränkungen zu überwinden. Erkennbar liefen diese Bemühungen parallel zu den Integrationsprozessen herrschaftlicher Macht, so daß diese beiden Entwicklungen sich gegenseitig stützten und verstärkten. Solche Synergieeffekte brachten allerdings Politik und Religion keineswegs näher zusammen, sondern beförderten im Gegenteil die Abgrenzung und schufen Ansatzpunkte für die Entflechtung ihrer strukturellen Organisationszusammenhänge. Das schloß die weitere erfolgreiche $\mathrm{Zu}$ sammenarbeit auf den verschiedenen Feldern, aber auch wechselseitige Anspriiche auf Kontrolle, wie wir das auch im orthodoxen Luthertum beobachten können ${ }^{139}$, nicht aus, war sogar eine der wesentlichen Voraussetzungen dafür.

\section{KATHOLISCHE KONFESSIONALISIERUNG ODER KATHOLISCHE REFORMEN?}

Blickt man über die habsburgischen Vorlande hinaus auf andere altgläubige Herrschaften und Gemeinwesen, so fallen zunächst in struktureller Hinsicht die Gemeinsamkeiten auf und nicht die Unterschiede. Die an den Vorlanden herausgearbeiteten strukturellen Zusammenhänge lassen sich, das hat die regionale Forschung gezeigt, mit Regelmäßigkeit auch anderswo finden. ${ }^{140} \mathrm{Va}$ -

137. Synodus 1567 (wie Anm. 87), S. 474 (Pars I, Tit. VI, Cap. VII); Synodus 1609 (wie Anm.64), S. 880 (Pars I, Tit. XVIII, Cap. X).

138. Vgl. Kurrus, Jesuiten (wie Anm. 135), S. 193 f.

139. Siehe hierzu nochmals Schorn-Schïtte, Obrigkeitskritik (wie Anm.13), S. 258264.

140. Ein Überblick ist jetzt leicht zu gewinnen durch Schindling, Ziegler (Hgg.), Die Territorien des Reichs (wie Anm. 8), Bde. 1-7. 
rianten ergeben sich eher aus der Intensität einzelner Abläufe und in ihrem zeitlichen Arrangement. Selbstverständlich ist auch die Einschränkung zu machen, daß die hier diskutierte ständische Konfrontation an die Existenz eines landsässigen Adelskorpus gebunden war, aber wo es, wie in Franken, fehlte, konnten schon ein Domkapitel oder Stände ohne Adel strukturell vergleichbare Konfliktlagen hervorbringen. ${ }^{141}$ Schließlich führten individuelle Entscheidungen bei Fürsten und Bischöfen zur Verzögerung oder Beschleunigung, auch zu eigenen Akzenten, aber dem strukturellen Gefüge konnte sich die Gestaltung der katholischen Reform nirgends völlig entziehen.

Es kann auf den ausgearbeiteten Vergleich an dieser Stelle ohnehin nicht ankommen. Es geht darum, die Besonderheiten der vorländischen Entwicklung zu akzentuieren.

Blickt man auf die weltlich-herrschaftliche Sphäre, so wird deutlich, daß die Bedeutung, die der Konfessionalisierungsprozeß für die Integration des Politischen gewinnen konnte, stark vom Zustand der Herrschaften abhing. Für kleine Herrschaften, wie die Fürstenberg und die Hohenzollern, die durch ihre geographische Lage im Feld der Konkurrenten sich zudem in gefährdeter Position befanden, lieferte die Konfessionalisierung Schubkraft für den Ausbau des Verwaltungsapparates und stärkte durch offenen oder versteckten Zugriff auf das Kirchenvermögen auch die herrschaftliche Finanzbasis. Es ist daher nicht verwunderlich, daß die Hohenzollern die Verwaltung der Kirchenfabriken zentralisierten und einer eigenen Behörde unterstellten. ${ }^{142}$ Gleichzeitig half der konfessionelle Gegensatz, strittige Herrschaftsansprüche $\mathrm{zu}$ untermauern. Das fürstenbergisch-badische Kondominat im Prechtal zeigt jedoch, daß die Kraft des konfessionellen Arguments keinesfalls stärker war als die des politischen. ${ }^{143}$ Entsprechend intensiv trat Landes-

141. Vgl. Ernst Schubert, Die Landstände des Hochstifts Würzburg, Würzburg 1967, S. 166 ff.; ders., Gegenreformationen in Franken, in: Jb. f. fränk. Landesforschg. 28 (1968), S. 275-305, hier: S. 281 f., 294 f., 299.

142. Huber, Hohenzollern (wie Anm. 116), S. 23 f.; sehr weitgehende Eingriffe sind auch in den Herrschaften der Grafen von Fürstenberg dokumentiert: Thoma, Fürstenberg (wie Anm. 78), S. 53 ff.

143. $\mathrm{Zu}$ den Entwicklungen im Prechtal vgl. oben Anm. 119. In kleineren Herrschaften ergaben sich hier auch Schwierigkeiten aus der Konfessionszugehörigkeit der rekrutierbaren Beamtenschaft: Ronald Asch, Verwaltung und Beamtentum. Die gräflich-fürstenbergischen Territorien vom Ausgang des Mittelalters bis zum Schwedischen Krieg 1490-1632, Stuttgart 1986, S. 229-234. Daß im Grunde eine nur lose Koppelung zwischen Territorialisierung und Konfessionalisierung bestand, zeigt im übrigen auch die Territorialherrschaft der Reichsprälaten. Entscheidende Schritte zu ihrem Aufbau erfolgten weitgehend unabhängig vom Konfessionalisierungsprozeß. Sie wurden be- 
herrschaft unter diesen Umständen im forum mixtum auf und forcierte den rechtlichen Zugriff auf die Geistlichkeit. Auch der Zugriff auf die Untertanen gewann eine intensive konfessionelle Färbung. Die Konfessionszugehörigkeit kann im Fürstenbergischen schon um 1600 als Untertaneneigenschaft im personalen Sinn bezeichnet werden. ${ }^{144}$ Nach unten gab es dafür ebenfalls eine Grenze: In den Herrschaftsbezirken der Reichsritterschaft mangelte es an kritischer Masse für eine erfolgreiche Verdichtung von Macht in Richtung Staatlichkeit. Sie blieben entsprechend auch „konfessionelle Niemandsländer“ ${ }^{145}$

In den katholisch gebliebenen Reichsstädten der Region ermöglichte die politische Autonomie dagegen eine noch sehr viel weitergehende Abgrenzung gegen die Bischofsgewalt als in den Territorien. Der Rat übernahm die nahezu vollständige Kontrolle der Temporalia, und es gelang die fast vorbehaltlose rechtliche Integration des städtischen Klerus in den Untertanenverband. ${ }^{146}$ Auch für die Legitimität der Herrschaftsausübung scheint die religiöse Begründung in den Kommunen früher Früchte getragen zu haben als in den Territorien. Die Reichsstädte lassen aber auch erkennen, daß eine Reihe dieser Effekte nur mittelbar mit der Ausdifferenzierung der Konfessionen verknüpft war. Bis zum Beginn des 17. Jahrhunderts blieb die Religionspolitik der Ratsgremien ihren rechtlichen und politischen Zielen nach spätmittelalterlich. ${ }^{147}$

Dies verweist auf einen weiteren Zusammenhang: Das Ausmaß, in dem obrigkeitliche Kirchenpolitik sich im strengen Sinn konfessionalistisch oder wenigstens reformorientiert gab, war abhängig vom Ausmaß der Herausforderung durch die neue Lehre. In den Vorlanden blieb sie lokal begrenzt und der Adel entdeckte dieses Instrument ständischer Opposition erst im letzten Drittel des 16. Jahrhunderts. Dagegen wurde in Bayern die schwierige dynastische Situation im Zusammenhang mit der Adelskrise der 1560er Jahre zur Initialzündung für eine konsequente und nachhaltige katholische Reform. ${ }^{148}$ In

reits getan, als dieser noch in den Anfängen lag: Maurer, Territorialgewalt (wie Anm.31), S. 157-172.

144. Thoma, Fürstenberg (wie Anm.78), S.146f.

145. So Volker Press 1981, hier zitiert nach Schindling, Konfessionalisierung (wie Anm. 10), S. 24.

146. Enderle, Konfessionsbildung (wie Anm.92), S. 218.

147. Ebd., S. 348, 397.

148. Vgl. Stefan Weinfurter, Herzog, Adel und Reformation. Bayern im Übergang vom Mittelalter zur Neuzeit, in: ZhF 10 (1983), S. 1-39; zu den Ereignissen siehe Walter Ziegler, Reformation und Gegenreformation 1517-1648. Altbayern, in: Walter Brandmïller ( $\mathrm{Hg}$.), Handbuch der bayerischen Kirchengeschichte, Bd.2: Von der Glaubensspaltung bis zur Säkularisation, Sankt Ottilien 1993, S. 1-64, hier: S. 25-35. 
ähnlicher Weise sahen sich die vorländischen Habsburger in ihrer Herrschaft durch die Verbreitung der evangelischen Lehre in Tirol herausgefordert und suchten die strukturellen Schwächen ihrer Herrschaft durch eine intensive und rigide katholische Reformpolitik auszugleichen. ${ }^{149}$

Hier wird eine Besonderheit der Vorlande greifbar: Spätestens nach 1534 mußte es mit der Restitution des württembergischen Herzogs für Habsburg aussichtslos erscheinen, diese Agglomeration an Herrschaftsrechten zu einem geschlossenen Territorium zu integrieren. Für eine spektakuläre Konfessionalität der Landesherrschaft bestand daher eigentlich kein Bedarf. Mit viel Wahrscheinlichkeit ist darauf auch zurückzuführen, daß die Intensität der herrschaftlichen Religionspolitik in Tirol augenscheinlich größer war als jenseits des Arlberg und nördlich des Bodensees.

Die kirchliche Integration im Prozeß der Konfessionalisierung folgte insgesamt dem territorialen Muster nur bedingt. Organisation und Hierarchie der römischen Kirche stellten andere, umfassendere Zusammenhänge her. Allein schon die Sessionen und Canones des Tridentinums gaben der Reform in den Bistümern einen gemeinsamen Bezugspunkt, der sie zu Varianten eines größeren Prozesses machte. Auch die Rolle der Jesuiten bei der Verfestigung und Ausgestaltung der konfessionellen Differenzierung ließ eine in den Institutionen und Glaubensformen homogene katholische Barocklandschaft entstehen. Breiter Spielraum blieb in der institutionellen Ausgestaltung des Verhältnisses von weltlicher und geistlicher Macht. Die geistlichen Erzstifte konnten in der Regel bis ins 18. Jahrhundert warten, bis die Trennung der geistlichen und weltlichen Sphäre zum Problem wurde. ${ }^{150}$ Der Konstanzer Bischof mußte dagegen schon am Beginn des 17. Jahrhunderts in der Formierung der Liga erleben, daß das Bistum in politischer Hinsicht bedeutungs- und machtlos geworden war. ${ }^{151}$

149. Vgl. die zusammenfassende Würdigung bei Bücking, Frühabsolutismus (wie Anm.39), S. 225-240; vgl. auch Günther Palaver, Das Ende der schamlosen Zeit. Die Verdrängung der Sexualität in der frühen Neuzeit am Beispiel Tirols, Wien 1987, S. 10-37, 50-123.

150. Siehe z. B. Marc R. Forster, The Counter-Reformation in the Villages. Religion and Reform in the Bishopric of Speyer, 1560-1720, Ithaca, London 1992, S. 117-143; Peter Hersche, Intendierte Rückständigkeit. Zur Charakteristik des geistlichen Staates im Alten Reich, in: Georg Schmidt (Hg.), Stände und Gesellschaft im Alten Reich, Stuttgart 1989, S.133-149; Schlögl, Glaube und Religion (wie Anm. 86), S. 127 ff.

151. Reinhard, Beziehungen (wie Anm. 27), S. 47. 


\section{SCHLUSS}

Die Ausgangsfrage war, warum die Differenzierung der Konfessionen sich institutionell festigen und zu eigenständigen Kirchentümern mit distinkter Dogmatik und klar unterscheidbaren Formen der Glaubenspraxis führen konnte. Die Forschung thematisierte unter dem Konfessionalisierungsparadigma den Verlauf dieses Prozesses gewiß zurecht, vernachlässigte damit aber, daß weder historische Notwendigkeit noch Zwangsläufigkeit in diesen Entwicklungen lag. Der festgestellte „Zwang zur Konfessionalisierung“ verdeckt dies ebenfalls. Die institutionelle Ausformung der Konfessionskirche ist wie auch die Ausdifferenzierung politischer Macht zu einem institutionellen Sonderbereich sozialer Ordnung vielmehr ein außerordentlich voraussetzungsvoller Vorgang, weil er quer zu bestehenden Strukturzusammenhängen lag. Noch genauer: Mit der Verdichtung frühmoderner Staatlichkeit und der Formung der Konfessionskirchen war zu beobachten, wie sich soziale Subsysteme als je eigenständige Handlungs- und Wertsphären ausformten, die das hierarchische Strukturprinzip durchbrachen, weil sie einander nicht mehr über- oder untergeordnet waren, sondern in der Verschiedenheit funktionaler Gleichwertigkeit nebeneinander standen. Nicht das Maß an Differenzierung nahm daher zu, sondern die Form der Differenzierung änderte sich an dieser Stelle. Die gesamte Frühe Neuzeit ist geprägt von diesem Umstellungsprozeß, von der Integration des Ökonomischen, des Rechts oder auch der Wissenschaft zu eigenständigen Sozialsystemen. Dieser Umstellungsprozeß durchbricht Epochengrenzen, wo immer sie von der Geschichtsschreibung auch gesetzt werden. Weder begann er erst um 1500 noch war er um 1700 schon zu einem Ende gekommen. Er prägt die Frühe Neuzeit, insofern er sie zu einer Epoche des fortgesetzten Zusammenbruchs bestehender Ordnungsmuster werden läßt. In ihr zersetzte sich eine soziale Ordnung, die in ihrem Grundmuster auf die hierarchische Gliederung sozialer Strukturen angelegt war, wie es in der Ständeordnung mit ihrer Adelsspitze zum Ausdruck kam. Als eigenständige soziale Handlungsbereiche konnten sich Religion und Politik nur gegen dieses hierarchische Differenzierungsmuster ausformen. Als Adelskirche war die Römische Kirche von dieser Umstellung im Kern betroffen. Daß sie in ihrer Struktur weiterhin eine wesentliche Stütze der frühneuzeitlichen Adelsgesellschaft blieb, gibt der katholischen Konfessionalisierung auch ihren eigenständigen Charakter.

Ich habe zu zeigen versucht, daß sich durch diesen Wandel der Strukturbildungsmuster der historische Ort der Konfessionalisierung bestimmt. Sie wirkte als Medium, das Problemlagen zusammenführte, die an sehr unter- 
schiedlichen Stellen der strukturellen Topographie frühneuzeitlicher Gesellschaften verortet waren. Auf diese Weise verbanden sich in ihr sehr disparate Veränderungen zu Prozessen der Strukturbildung, die sich schließlich stabilisierten. ${ }^{152}$ In diesem Sinn ist weder die Konfessionalisierung allgemein noch in ihrer katholischen Variante im besonderen ein gesellschaftlicher Fundamentalprozeß, wohl aber Symptom eines solchen Vorganges. Wird Konfessionalisierung andererseits primär mit (staatlich betriebener) Kirchenbildung identifiziert, die auf weiteren gesellschaftlichen Feldern nicht intendierte Folgewirkungen zeitigte, so setzt die Analyse im Kern schon voraus, was erst Ergebnis der komplexen Entwicklung war: die Separierung unterschiedlicher sozialer Kommunikations- und Handlungssysteme.

Statt dessen wird hier vorgeschlagen, Konfessionalisierung als offenes $\mathrm{Ge}$ schehen zu behandeln, das multizentrisch ablief und auf unterschiedlichen Ebenen der sozialen Ordnung auch unterschiedliche Erfahrungswirklichkeiten produzierte. Dies kann darüber hinaus den Weg in die Moderne als prozeßhaftes Geschehen veranschaulichen, das sich aus Umgestaltungsvorgängen unterschiedlichster Art, Geschwindigkeit und auch Eigenrationalität zusammenfügte und deswegen keineswegs zielgerichtet vor sich ging. Damit wären auch einige Schwierigkeiten zu umgehen, die sich mit dem Begriff der Sozialdisziplinierung zwischenzeitlich verbinden. Es ist nicht von der Hand zu weisen, daß er Staatlichkeit in einer Kompaktheit und Dichte unterstellt, die eigentlich doch erst im Entstehen begriffen war. Wir haben daher hier auf ihn weitgehend verzichtet. Deswegen ist auch die Frage neu zu stellen, in welcher Weise Konfessionsbildung einen Beitrag zur Begründung und Implementierung des neuzeitlichen Individualismus oder zur Freisetzung des abendländischen Rationalismus auch im Vergleich zu Veränderungen in anderen Segmenten der Gesellschaft leistete, sie also modernisierend wirkte.

Mit dieser Frage ist zunächst schon unterstellt, daß die europäische Zivilisation in der Trennung von weltlicher und geistlicher Herrschaft, wie sie sich im Hochmittelalter durchsetzte, einen eigenständigen Entwicklungstypus be-

152. Die Grenzziehung zwischen Religion und Politik ist in dieser Perspektive ein Sekundärproblem, das aus der neuen Differenzierungsform sich erst ergibt, aber nicht den Problemzusammenhang konstituiert. Vgl. dazu auch Luise Schorn-Schïtte, Lutherische Konfessionalisierung? Das Beispiel Braunschweig-Wolfenbüttel (1589-1613), in: Hans-Christoph Rublack (Hg.), Die lutherische Konfessionalisierung in Deutschland. Wissenschaftliches Symposion des Vereins für Reformationsgeschichte 1988, Gütersloh 1992, S. 163-194, bes. S. 165 ff. Mit anderer Terminologie, aber in der hier entfalteten Argumentationslinie: Stolleis, „Konfessionalisierung" (wie Anm.10), bes. S. $11 \mathrm{ff}$. 
gründete, der die Voraussetzungen für die Rationalisierung der Lebenszusammenhänge wie für eine Säkularisierung gesellschaftlicher Ordnung gleichzeitig bot. Die in der europäisch-christlichen Welt angestoßene Evolution einer stratifizierten Hochkultur zur funktionalen Moderne begründet die weltgeschichtliche Sonderrolle des christlichen Europa und hat in diesem „kontingenten" Ereignis eine wesentliche Voraussetzung. Heinz Schilling hat diesen Sachverhalt neuerdings nochmals in Erinnerung gerufen. ${ }^{153}$ Diese Verklammerung der Entwicklungsstränge führte aber auch dazu, daß das Verhältnis von geistlicher und weltlicher Macht immer von den Differenzierungsmustern der sozialen Ordnung geprägt blieb. Auf europäischer Ebene zeigte sich dies an der Wende vom 15. zum 16. Jahrhundert ganz deutlich daran, daß die sich konsolidierenden Monarchien Englands und Frankreichs zielstrebig eine nationalkirchliche Emanzipation aus der papalen Hegemonie realisierten und die weltlichen Herrschaftsrechte der Kirche entsprechend transformierten in Frankreich sogar in Zusammenarbeit mit den Bischöfen. Auch im Reich drängte die Reformprogrammatik des 15 . Jahrhunderts samt dem Konkordat Friedrichs III. und dem Ausbau des Kirchenregiments im sich formierenden Territorialstaat in eine nationalkirchliche Richtung. Selbst die Reformation trug bis zum Augsburger Religionsfrieden im Vorschlag, das Schisma auf einem Nationalkonzil zu überwinden, ein explizit nationalkirchliches Versprechen in sich. Es wurde zwischen universaler Kaiseridee und territorialer Staatsbildung zerrieben. Die gegen die Adelskirche gerichteten Intentionen des Tridentinums blieben ebenfalls weitgehend unverwirklicht. Aus dieser Perspektive erscheinen Reformation und Konfessionalisierung nicht mehr als universalhistorische Notwendigkeiten, sondern als funktionales Äquivalent nationalkirchlicher Organisation. Als ein Äquivalent allerdings, das auch entschiedene Vorteile gegenüber der nationalkirchlichen Variante bot, weil es die soziale Organisationskraft von Religion sowohl für die Kirche wie auch für den Bereich politischer Macht aus der Konfrontration dogmatischer Differenzbildung heraus in Kombination mit dem Fundamentalismus des alltagsweltlichen Geltungsanspruches von Religion erheblich stärkte.

Weder der strukturelle Ort von Reformation und Konfessionalisierung im universalhistorischen Entwicklungszusammenhang noch auch die strukturellen Parallelen im Konfessionalisierungsgeschehen selbst legen es deswegen nahe, der konfessionellen Kirchenbildung allzuviel Eigengewicht oder eine Sonderstellung in der evolutionären Modernisierung der frühneuzeitlichen Gesellschaft zuzumessen. $\mathrm{Da}$ in allen Konfessionen schließlich vergleichbare

153. Schilling, Der religionssoziologische Typus Europa (wie Anm. 10). 
Antworten auf ähnliche Problemlagen gefunden wurden, ist die Frage berechtigt, ob nicht Theologie und Institutionenapparat einer zu nationalen Kirchentümern ausgefalteten Römischen Kirche diese Kräfte ebenfalls hätte entwickeln können. Wichtiger für die angesprochenen Veränderungen und das religiöse Rationalisierungspotential waren möglicherweise die semantischen Alternativen und die neuen Diskurs- und Wissensformen, die sich unter dem Dach der Reformation entfalten konnten. ${ }^{154}$

Stellt sich der historische Blick auf Differenzierungsvorgänge und Differenzierungsmuster ein, nimmt er nicht nur die hier beschriebene Ausdifferenzierung von Macht und Religion wahr, sondern auch die fortschreitende Integration anderer sozialer Kommunikationszusammenhänge im Verlauf der Frühen Neuzeit. Diese zunehmende Verselbständigung weiterer Handlungssphären und ihre Stabilisierung durch generalisierte Kommunikationsmedien reduzierte nach und nach zwangsläufig die Reichweite religiöser Handlungsrationalität. Damit wird nicht nur zweifelhaft, ob religiöse Normen wirtschaftliches Handeln steuern, sondern ob Handlungsmotive ïberhaupt die Entfaltung von Strukturmustern beeinflussen können. ${ }^{155}$ Es verhält sich vielmehr umgekehrt: Die beispielsweise ökonomischen Konsequenzen von Handeln ergeben sich aus Strukturzusammenhängen und nicht aus Handlungsmotiven. ${ }^{156}$ Damit ist nicht die handlungsorientierende Kraft des asketischen Protestantismus bestritten, wohl aber seine strukturbildende Wirkung, die Max Weber unterstellte.

Unterschiedliche Pfade in die Moderne dürfte die Konfessionalisierung also kaum begründet haben. Überdies ist deutlich: Manche ihrer „Errungenschaften" mußten nachträglich erst wieder rückgängig gemacht oder neutralisiert werden, um den Weg zur toleranten Bürgergesellschaft der Moderne zu ebnen. ${ }^{157}$ Schon das 18 . Jahrhundert konnte sich nicht mehr vorstellen, religiös verortete Individualität und Subjektivität in der interaktiven Kommunika-

154. Vgl. Thomas Fuchs, Protestantische Heiligen-memoria im 16. Jahrhundert, in: HZ 267 (1998), S. 587-614.

155. Luhmann, Gesellschaftsstruktur, Bd.3 (wie Anm. 2).

156. Wolfgang Reinhard hat diesen Punkt in der Explikation des Konfessionalisierungsparadigmas in einer anderen Beschreibungssprache immer wieder betont, wenn er darauf insistierte, daß Handeln stets mit unbeabsichtigten Folgen verbunden ist, auf die es dem Historiker ankommen muß. Der systemtheoretische Bezug dieser Argumentationsfigur wird jetzt noch deutlicher in Wolfgang Reinhard, Geschichte der Staatsgewalt. Eine vergleichende Verfassungsgeschichte Europas von den Anfängen bis zur Gegenwart, München 1999, S. 19-23.

157. Mörke, ,Konfessionalisierung' (wie Anm. 14 ), S. 51 ff.; Winfried Schulze, Concordia, Discordia, Toleranzia. Deutsche Politik im konfessionellen Zeitalter, in: Jo- 
tion der Geselligkeit zu bearbeiten. Man riet dazu, religiöse Fragen in Geselligkeit nicht zu thematisieren oder verbot es ausdrücklich, wie in den Freimaurerlogen. Johann Salomo Semler stritt für die „Privatreligion“. Hier tritt an einer ganz anderen Stelle dann doch noch einmal zum Vorschein, wie eng und gleichzeitig paradox Konfessionalisierung und Säkularisierung miteinander verbunden waren.

Prof. Dr. Rudolf Schlögl

Universität Konstanz

Fachbereich Geschichte und Soziologie

Fach D5

78457 Konstanz

\begin{abstract}
Using the example of the Habsburg lands, the author reformulates the paradigm of confessionalization in the light of system theory. Confessionalization is understood as symptom of a reorganization which deeply affected the entire social structure. The process of confessionalization brought about the disintegration of the hierarchical patterns of feudal society and the slow integration of religion and politics as functionally related systems of action with their own social rationality of action. From the perspective of the prince, the confessionalization of the Vorlande meant the creation of clearly marked boundaries between the secular and the ecclesiastical sphere of influence. This made it increasingly difficult to employ secular titles of possession for ecclesiastical purposes and vice versa. On the other hand, the prince used his religious and secular reform policy in order to bypass the nobility and to bring his princely authority to bear directly upon his subjects. In this way, confessionalization contributed decisively to the formation of a state independent of the nobility. There were analogous developments in the ecclesiastical sphere. The process of confessionalization brought about the reorganization of the Adelskirche and its structure based on benefices into a bureaucratic organization centered on the bishop and staffed by an educated clergy committed to a special, i.e. non-noble, way of life. At the same time, the church succeeded in extending its legal autonomy vis-à-vis the secular government. With the Tridentine reform of piety, the division between the holy and the profane also became clearer in other areas of life. This furthered the separation of the religious sphere from other fields of social interaction. Therefore, confessionalization became possible because it was linked with the complex processes of integration, in the course of which religion and politics developed into social systems independent of one another. Hence it has to be doubted whether confessionalization qualifies as a fundamental process of society. It should rather be understood as a part of a comprehensive and thorough process of restructuring. Therefore, the significance of confessional church-building in the evolutionary process of modernization in early modern society will have to be newly defined.
\end{abstract}

hannes Kunisch (Hg.), Neuere Studien zur frühneuzeitlichen Reichsgeschichte, Berlin 1987, S. 43-79, bes. S. $71 \mathrm{ff}$. 